Morphosyntactic Production and Verbal Working Memory: Evidence from Greek Aphasia and Healthy Aging

Valantis Fyndanis ${ }^{1,2}$, Giorgio Arcara ${ }^{3}$, Paraskevi Christidou ${ }^{4}$, David Caplan ${ }^{5}$

${ }^{1}$ MultiLing/Department of Linguistics and Scandinavian Studies, University of Oslo, Oslo, Norway

${ }^{2}$ Department of Linguistics, University of Potsdam, Potsdam, Germany

${ }^{3}$ IRCCS Fondazione Ospedale San Camillo, Venice Lido, Italy

${ }^{4}$ Evexia Rehabilitation Center, Thessaloniki, Greece

${ }^{5}$ Neuropsychology Laboratory, Massachusetts General Hospital, Boston, USA

Corresponding author: Valantis Fyndanis (valantis.fyndanis@iln.uio.no )

Address of corresponding author: Postboks 1102 Blindern 0316 Oslo, Norway

Keywords: aphasia, morphosyntactic production, working memory, locality 


\begin{abstract}
Purpose: The present work investigated whether verbal working memory (WM) affects morphosyntactic production in configurations that do not involve or favor similarity-based interference, and whether WM interacts with verb-related morphosyntactic categories and/or cue-target distance (locality). It also explored whether the findings related to the questions above lend support to a recent account of agrammatic morphosyntactic production: Interpretable Features' Impairment Hypothesis (IFIH: Fyndanis, Varlokosta, \& Tsapkini, 2012).
\end{abstract}

Method: A sentence completion task testing production of subject-verb agreement, tense/time reference, and aspect in local and nonlocal conditions and two verbal WM tasks were administered to eight Greek-speaking persons with agrammatic aphasia (PWA) and 103 healthy participants.

Results: The three morphosyntactic categories dissociated in both groups (agreement $>$ tense $>$ aspect). A significant interaction emerged in both groups between the three morphosyntactic categories and WM. There was no main effect of locality in either of the two groups. At the individual level, all eight PWA exhibited dissociations between agreement, tense and aspect and effects of locality were contradictory. Conclusions: Results suggest that individuals with WM limitations (both PWA and healthy older speakers) show dissociations between the production of verb-related morphosyntactic categories. WM affects performance shaping the pattern of morphosyntactic production (in Greek: subject-verb agreement $>$ tense $>$ aspect). The absence of an effect of locality suggests that executive capacities tapped by WM tasks are involved in morphosyntactic processing of demanding categories even when the cue is adjacent to the target. Results are consistent with the IFIH (Fyndanis et al., 2012). 


\title{
Morphosyntactic Production and Verbal Working Memory: Evidence from Greek Aphasia and Healthy Aging
}

\author{
The majority of studies on the relationship between working memory (WM) and \\ language processing have focused on language comprehension. Many studies \\ concluded that WM is critically involved in (morpho)syntactic comprehension (e.g., \\ Almor, MacDonald, Kempler, Andersen, \& Tyler, 2001; Caplan \& Waters, 1995, \\ 1999; Haarmann, Just, \& Carpenter, 1997; Just \& Carpenter, 1992; King \& Just, \\ 1991; Kolk, Chwilla, Van Herten, \& Oor, 2003; Lukatela, Shankweiler, \& Crain, \\ 1995; Roberts \& Gibson, 2002; Waters \& Caplan, 2002; but see Caplan \& Waters, \\ 2013, and MacDonald \& Christiansen, 2002). \\ The relationship between WM and (morpho)syntactic processing in
} production - which is alternatively termed grammatical encoding (Martin \& Slevc, 2014) — has been much less researched. Grammatical encoding consists of two components, the functional assembly, which involves the selection/retrieval of lexical and grammatical units that convey the intended message, and the structural assembly, which involves the selection and retrieval of syntactic representations that convey relational and perspective meaning (Ferreira \& Slevc, 2007; Martin \& Slevc, 2014).

There are contrasting views regarding the role of WM in grammatical encoding. According to Levelt (1989), the processes involved in grammatical encoding are largely automatic, which means that WM- a controlled system — is not critically involved in this stage of the sentence production process. On the other hand, several studies suggest — explicitly or implicitly — that WM plays an important role in grammatical encoding (e.g., Ferreira \& Pashler, 2002; Garrett 1982; Smith \& Wheeldon, 2001; Slevc \& Martin, 2016; Hartsuiker \& Barkhuysen, 2006). Two recent 
studies, Slevc and Martin (2016) and Hartsuiker and Barkhuysen (2006), focused on the production of subject-verb agreement in configurations that favor agreement attractions errors. It has been shown that intervening noun phrases (or, alternatively, determiner phrases) that are semantically closely related to the subject (e.g., The key to the cabinets..., The drawing of the flowers...) often lead to increased agreement attraction errors (The key to the cabinets *are...; The drawing of the flowers *are...) (e.g., Bock \& Miller, 1991; Bock \& Cutting, 1992; Solomon \& Pearlmutter, 2004). Slevc and Martin (2016) and Hartsuiker and Barkhuysen (2006) argued that agreement attraction errors reflect WM processes and result from similarity-based interference. In particular, Slevc and Martin (2016, p. 773) suggested that "producing an agreeing verb involves a cue-based search in WM for an appropriate controlling noun, which is subject to interference from other elements in memory with similar properties" (p. 773) (see also Badecker \& Kuminiak, 2007). For example, in the ungrammatical sentence The key to the cabinets *are on the table, the speaker had to encode in the verb the number value carried by the subject of the sentence the key (i.e., singular); however, the number value of the intervening noun phrase the cabinets (i.e., plural) interfered with the number value of the subject noun phrase the key (i.e., singural), which led to an agreement attraction error, that is, the retrieval and production of the verb form are (instead of $i$ ).

It might be the case, however, that WM limitations can also affect aspects of morphosyntactic production that do not involve similarity-based interference. Kok, van Dorn and Kolk (2007), for example, found that WM affected the production of subject-verb agreement and tense in sentences that did not favor agreement attraction. The authors administered a sentence completion task (among other experiments) in which participants were presented with a written sentence from which the verb was 
missing and with the infinitival form of the missing verb. Both the grammatical subject and the temporal adverb were adjacent to the space indicating the missing verb (e.g., Het meisje ___ tegenwoordig vaak de vloer (dweilen), The girl nowadays often the floor (to mop)). (In this task, the participant was required to read aloud the sentence providing the missing finite verb form.) Furthermore, in a recent account of the selectively impaired morphosyntactic production in agrammatic aphasia, Fyndanis, Varlokosta and Tsapkini (2012) formulated the Interpretable Features' Impairment Hypothesis (IFIH), whose predictions are consistent with the conceptualization of verbal WM as a limited-capacity system that places constraints on the processing of morphosyntactic phenomena that are demanding even without the involvement of similarity-based interference (see also Fyndanis, Manouilidou, Koufou, Karampekios, \& Tsapakis, 2013). According to the IFIH, categories involving integration processing (such as tense/time reference and aspect) are more demanding in terms of processing resources than categories that do not involve integration processes (such as subject-verb agreement). Hence, speakers with limited processing resources/limited WM capacity (such as persons with aphasia or Alzheimer's disease) are more impaired in the production of tense and aspect compared to the production of subject-verb agreement. ${ }^{1}$ Certainly, this is expected to

\footnotetext{
${ }^{1}$ This hypothesis has been formulated within the framework of Minimalist Program (Chomsky, 1995, 2000, 2001), according to which subject-verb agreement bears an uninterpretable feature, and tense and aspect bear interpretable features. This is so because the marking of person and number on the verb does not contribute to semantic interpretation, whereas the marking of tense and aspect on the verb does. Categories with uninterpretable features involve processing of grammatical information only, while categories with interpretable features require processing and
} 
be the case when subject-verb agreement is produced in configurations that do not favor agreement attraction. (The IFIH does not challenge the view that WM limitations can also arise from similarity-based interference.) Thus, according to the IFIH (Fyndanis et al., 2012), a limited (verbal) WM capacity should affect the production of categories involving integration processes (such as tense and aspect), but not the production of categories that do not involve integration processes (such as subject-verb agreement). This hypothesis has not been tested adequately thus far. To our knowledge, only Fyndanis et al. (2017) tested this hypothesis correlating verbal WM scores with accuracy scores of 16 Greek-speaking and 10 Italian-speaking individuals with probable Alzheimer's disease on the production of subject-verb agreement (-integration processes), tense (+integration processes) and mood (+integration processes). Fyndanis et al. (2017) found all three morphosyntactic phenomena to be positively correlated with WM scores to a similar extent in both groups, but only the correlations in the Greek group were significant. These findings do not lend full support to the IFIH (Fyndanis et al., 2012) but they should be treated with caution, because of the small number of participants that entered the correlational analyses.

An additional variable that is potentially relevant to morphosyntactic production and WM is the distance between the cue and the target. Several studies on morphosyntactic production in aphasia have not controlled for this variable and - to our knowledge — no study has manipulated it. Nanousi, Masterson, Druks and Atkinson (2006), for example, administered transformational sentence completion tasks in which there were no intervening phrases between the cue and the target in the integration of information from two distinct levels of representation (i.e., grammatical and extralinguistic/conceptual). 
subject-verb agreement condition (see 1) but, in the tense condition, a noun phrase intervened (see 2).

(1) Source Sentence: XӨés to ayóri perpátise

'Yesterday the boy walked-sg'

Target Sentence: XӨés ta ajórja (target: perpátisan)

'Yesterday the boys ___ _ ' (target: walked-pl.)

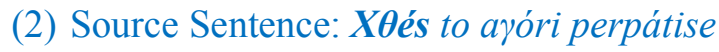

'Yesterday the boy walked'

Target Sentence: 'Avrio to ayóri ' (target: Aa perpatísi)

'Tomorrow the boy ' (target: will walk)).

This study found tense more impaired than agreement, but this might be (at least partly) attributable to this between-condition difference. There are similar confounds in Fyndanis et al.'s (2012), Gavarrò and Martínez-Ferreiro’s (2007), and Varlokosta Varlokosta, Valeonti, Kakavoulia, Lazaridou, Economou and Protopapas’ (2006) studies. The distance between the two elements of a binding relation or of a subjectverb dependency has been reported to affect aspects of sentence comprehension (e.g., Gibson, 1998, 2000; McElree, 2000; for similar findings from studies on aphasia and the elderly see also Baum, 1989; Sung, 2009; but see Friedmann \& Gvion, 2003). Assuming that sentence comprehension and sentence production are interwoven and that both comprehenders and speakers make predictions regarding the values of the features that the upcoming verb will encode (see Pickering \& Garrod, 2013), one could hypothesize that distance plays a role also in the production of morphosyntactic dependencies. In grammatical encoding, a speaker often retrieves finite verbs that 
encode multiple features at the same time, such as person and number features (subject-verb agreement), time reference/tense (reference to the past, reference to the present, reference to the future), aspect (perfective aspect, imperfective aspect), and voice (active voice, passive voice). Regardless of the scoring criteria, in sentence completion tasks used to investigate morphosyntactic production, the participant tries to retrieve a verb form that is consistent with all features carried by the preceding material (grammatical subject and adverbials). For example, to retrieve the target verb form in the Greek target sentence in (3), the speaker has to store and/or retrieve the prephonological features FUTURE, SINGULAR, $1^{\text {st }}$ PERSON, and PERFECTIVE $(\mathrm{ASPECT})^{2}$

(3) Source Sentence: XӨés eyó mésa se mná óra épsisa tis brizóles.

'Yesterday I within an hour grilled- ${ }^{\text {st }}$.sg.perfective the steaks (lit.)' Target Sentence: Ávrio eyó mésa se mná óra

(target: $\theta$ a psíso- $1^{\text {st }}$. sg.perfective tis brizóles)

'Tomorrow I within an hour (lit.)

(target: will grill- $1^{\text {st. }}$.sg.perfective the steaks)

If the completion of sentences like (3) requires the active maintenance of these features in verbal WM (see Ness \& Meltzer-Asscher, 2017, and references therein), and if this storage demand exceeds the capacity of the storage component of the

\footnotetext{
${ }^{2}$ It is clear that sentence completion tasks involve aspects of both comprehension (the participant has to process the material that precedes the target) and production (the participant has to produce the target, which must be consistent with the preceding material).
} 
speaker's WM system, the speaker will likely retrieve a verb form that is not consistent with all features of the preceding material. If distant features are subject to time-based decay (e.g, Barrouillet \& Camos, 2012), it is possible that they will not be stored. If this is the case, the production of a given morphosyntactic category should be more successful when its controller (the cue) is adjacent to the verb than when it is distant. Some evidence for that has been provided by Fyndanis, Nerantzini, Choudala, and Tsapakis (2014), who reported a Greek-speaking agrammatic individual who showed locality effects in the production of tense and subject-verb agreement.

Exploring the role of verbal WM and cue-target distance in morphosyntactic production will shed more light on grammatical encoding, which is an understudied topic in psycholinguistics and cognitive (neuro)psychology. This investigation will also advance our understanding of the nature of the deficit in morphosyntactic production in agrammatic aphasia, as its results will be discussed in light of a recent account of agrammatic production, the IFIH (Fyndanis et al., 2012).

\section{The present study: Research questions and predictions}

This study addressed three interrelated questions:

(1) Does verbal WM affect morphosyntactic production even in configurations that do not involve or favor similarity-based interference?

(2) Does verbal WM interact with verb-related morphosyntactic categories (in particular, subject-verb agreement, tense/time reference, and aspect) and/or cue-target distance (locality)?

(3) Do the findings related to (1) and (2) lend support to the IFIH (Fyndanis et al., 2012)?

Note that, in many countries, it is extremely difficult to recruit a large number 
of participants who meet the criteria for agrammatic aphasia. We are aware of no study on Greek agrammatic aphasia that reports more than 10 patients. A viable alternative to testing a large cohort of language/cognitively-impaired speakers, such as PWA, in order to explore the role of WM in sentence production is to test a relatively small group of language/cognitively-impaired individuals and a large cohort of healthy speakers who vary in their WM capacity. Miyake, Carpenter, and Just (1994) and Dick, Bates, Wulfeck, Utman, Dronkers, and Gernsbacher (2001) showed that pathology exacerbates behavioral patterns observed in healthy individuals. Thus, even if a possible significant interaction of WM with morphosyntactic phenomena is not detectable in a relatively small sample of language/cognitivelyimpaired participants, probably this interaction can be detected in a large cohort of healthy speakers who vary in their WM capacity. If both the small group of PWA and the large cohort of healthy participants yield similar results, this will be compelling evidence for or against the hypothesis being tested.

As will be shown in the Methods section, to address the above questions we tested eight Greek-speaking persons with agrammatic aphasia (PWA) and 103 healthy individuals aged 22-86. We included younger, middle-aged and older speakers because we wanted to maximize variability in verbal WM capacity within the healthy speakers' group (Salthouse, 1992, 1996; Waters \& Caplan, 2005).

Because of its relatively free word order (Holton, Mackridge, \& PhilippakiWarburton, 1997), Greek lends itself for manipulating the distance between the cue and the target (locality variable) when testing subject-verb agreement, tense, and aspect. 
Based on the fact that the majority of studies on aphasia report dissociations between verb-related morphosyntactic categories, with subject-verb agreement better preserved than tense and aspect, we make the following predictions.

(1) We expect WM to affect the production of inherently demanding morphosyntactic categories, such as tense and aspect, despite the fact that these categories are never subject to similarity-based interference (see Methods).

(2) We expect levels of performance on morphosyntactic production to be related to verbal WM capacity. If indeed tense and aspect are more demanding than subject-verb agreement in terms of processing resources, we expect WM to affect tense and aspect more than subject-verb agreement. We also expect participants with a limited WM capacity to perform better on local than on nonlocal dependencies.

(3) Assuming that subject-verb agreement, tense and aspect pose differential demands on verbal WM (Fyndanis et al., 2012, 2013), and given that PWA and healthy older speakers have a limited verbal WM (Kok et al., 2007; Salthouse, 1992, 1996; Waters \& Caplan, 2005), we expect agreement to elicit better performance than tense/time reference and aspect (see prediction 2). Hence, we expect the findings to be consistent with the IFIH (Fyndanis et al., 2012).

Before proceeding to the Methods section, we briefly give relevant background information on Greek. Greek verbs consist of a stem and one or more inflectional suffixes that express morphosyntactic phenomena such as subject-verb agreement and tense (past, present, future, among others). In subject-verb agreement, there are three persons $\left(1^{\text {st }}, 2^{\text {nd }}, 3^{\text {rd }}\right)$ and two numbers (singular, plural), the combination of which yields six different suffixes in each tense (Holton et al., 1997). Stems encode another morphosyntactic (functional) category, aspect (perfective, imperfective, among 
others). Aspect interacts with tense, as in the vast majority of verbs there are distinct verb forms encoding past perfective, past imperfective, future perfective and future

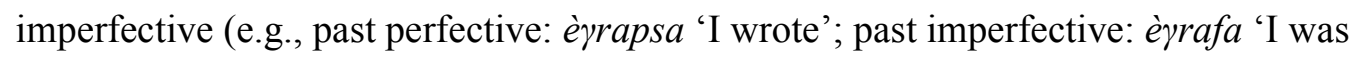
writing/I used to write'; future perfective: $\theta a$ rráfo 'I will write'; future perfective: $\theta a$ rrápso 'I will write') (op. cit.).)

\section{Methods}

\section{Participants}

Eight Greek-speaking PWA (mean age $=69.1, \mathrm{SD}=10.7$; years of formal education: mean $=9.3, \mathrm{SD}=4.2$, and one hundred and three neurologically-intact native speakers of Greek (mean age $=50, \mathrm{SD}=19$; years of formal education: mean $=13.6$, $\mathrm{SD}=4.5), 29$ male, participated in the study.

All brain-damaged participants developed aphasia following cerebrovascular accidents (CVA) in the left hemisphere. Presence of aphasia and aphasia type were diagnosed on the basis of clinical presentation and the published Greek standardized version of the Boston Diagnostic Aphasia Examination-Short Form (BDAE-SF) (Goodglass, Kaplan, \& Barresi, 2001; 2013). Aphasic participants' agrammatism was diagnosed on the basis of samples of semispontaneous speech elicited using picture description (Cookie Theft) and stroke stories. The speech samples were analyzed following the coding procedures described in Thompson, Shapiro, Tait, Jacobs, Schneider, and Ballard (1995). Evidence for agrammatism was considered the combination of a relatively low proportion of grammatical sentences and a relatively reduced Mean Length of Utterance (MLU) (Faroqi-Shah \& Thompson, 2004). Individuals diagnosed with different aphasia types (Broca's aphasia, transcortical 
motor aphasia, anomic aphasia, conduction aphasia) participated in this study but all of them had agrammatic production.

The healthy speakers sampled the whole adult age range (22-86), yielding a relatively even distribution across lifespan decades (Fig. 1). The Mini Mental State Examination (MMSE) (Folstein, Folstein, \& McHugh, 1975; Fountoulakis, Tsolaki, Chantzi, \& Kazis, 2000) was administered to older speakers (>60) to exclude participants presenting signs of dementia. Only individuals who scored at least 27/30 on MMSE were tested. A subset $(\mathrm{N}=8)$ of the large group of the healthy participants served as a control group for the aphasic group. These two groups were matched on age (Welsh t-test: $\mathrm{t}(13.107)=-0.129, p=0.890)$ and years of formal education (Welsh t-test: $\mathrm{t}(13.934)=0.434, p=0.671)$, and their data formed Dataset 1 . Aphasic and control participants' demographic and speech data are presented in Table 1. The scale profile of speech characteristics for the aphasic participants is given in Supplementary Materials 1 . The data of the large group of healthy participants $(\mathrm{N}=103)$ formed Dataset 2.

(Insert Figure 1 about here)

(Insert Table 1 about here)

\section{Experiments}

\section{Assessment of Working Memory}

We measured participants' verbal WM capacity by means of two complex span tasks

- the Greek version of the digit ordering span task developed by Fyndanis et al. (2013) (which in turn was based on MacDonald, Almor, Henderson, Kempler, \& 
Andersen, 2001) and a Greek research version of the backward digit span task (based on Wechsler, 2008). The backward digit span task and the digit ordering span task have been often used to measure the verbal WM capacity of healthy and neurologically affected individuals, as both of them involve storage and processing components (e.g., Francis, Clark, \& Humphreys, 2003; MacDonald et al., 2001; Mayer \& Murray, 2002; Murray, Keeton, \& Karcher, 2006; Nittrouer, Lowenstein, Wucinich, \& Moberly, 2016; Potagas, Kasselimis, \& Evdokimidis, 2011). The backward digit span task has "relatively good psychometric properties in terms of test-rest reliability" (Salis, Kelly, \& Code, 2015, p. 730). The instructions are easy to follow, which makes these tasks well-suited for neurologically affected individuals (for the digit ordering span task, see MacDonald et al., 2001).

In the digit ordering span task, participants hear a series of digits (e.g., 2, 8, 5, $4)$ and immediately report them back in ascending numerical order $(2,4,5,8)$. The task included five levels of difficulty, which ranged from two to six digits to order. Each level consisted of three (equal length) series of digits. In the backward digit span, the participant hears a series of digits (e.g., 2, 8, 5, 4) and immediately reports them back in reverse order of presentation $(4,5,8,2)$. This task included seven levels of difficulty, which ranged from two to eight digits. Each level consisted of two (equal length) series of digits. In both WM tasks, the digits 1-9 were used to develop the experimental digit series. For both tasks, we used the scoring criteria employed by MacDonald et al. (2001), and following Waters and Caplan (2003) we calculated composite WM scores. 


\section{Morphosyntactic production}

\section{Materials}

A sentence completion task was developed, which tested subject-verb agreement, tense, and aspect. One hundred and ninety-two experimental source sentence-target sentence pairs overall were created, 64 testing production of each morphosyntactic category. In the agreement condition, person and number agreement were tested, and there were no grammatical subjects with a conflict between grammatical and notional number (Humphreys \& Bock, 2005). In the tense condition, past-tensed and futuretensed verb forms were elicited. In the aspect condition, perfective and imperfective aspect were targeted. Each cue contained one or two features that were relevant for the to-be-produced verb. The grammatical subjects carried two features (person, number) and the temporal and aspectual adverbials carried one feature (tense/time reference feature and aspect feature, respectively). As can be seen in Table 2, the source sentences always differed from the target sentences only in one feature value conveyed by the subject or an adverbial (person, number, tense/time reference, or aspect), which was sufficient to trigger the production of the target verb form associated with the morphosyntactic category under consideration for each item. The configurations included in the distant dependency version of the tense and aspect conditions did not involve similarity-based interference, because in these conditions neither the intervening subject nor the intervening adverbial could interfere with the experimental cue (that is, the temporal or the aspectual adverbial); all three preverbal phrases (temporal adverbial (adverb phrase), aspectual adverbial (prepositional phrase), subject noun phrase) carried different features (tense/time reference, aspect, person and number). The configurations included in the distant dependency version of the subject-verb agreement condition did not favor similarity-based interference for 
two reasons. First, in the sentences included in this condition, none of the intervening phrases was a postmodifier of the head noun phrase (the subject). It has been shown that prepositional phrases that modify or complement the subject noun phrase tend to be more "semantically integrated" with it than prepositional phrases that do not modify it (Solomon \& Pearlmutter, 2004), a factor which favors agreement attraction errors. Second, in the agreement condition all subjects were animate and all intervening noun phrases (which were part of the aspectual adverbials) were inanimate. Animacy appears to play a role in determining subjecthood (see Bock, Loebell, \& Morey, 1992), and, in subject-verb agreement, the person and number values of the animate - and thus semantically prototypical — subject might be more resistant to similarity-based interference effects compared to structures such as The key to the cabinets...., where both noun phrases are inanimate.

\section{(Insert Table 2 about here)}

Sixteen bisyllabic regular transitive (two-place) verbs were used, all stressed on the penultimate syllable. Each of these verbs appeared six times, i.e. in the nonlocal and local dependency versions of the subject-verb agreement, tense, and aspect conditions (see below). All three conditions, in both the nonlocal and local versions, were matched on sentence length.

In each morphosyntactic category, half the items involved local dependencies (no intervening phrases between the cue and the target), and half nonlocal dependencies; in the latter, two short phrases_-noun phrase (subject) and/or adverbial(s))__intervened between the cue and the target (see Table 2). We took the number of phrases, not the number of words or syllables, as the measure of linear cue- 
target distance. ${ }^{\mathrm{i}}$ Based on current linguistic analyses of the structure of the sentences (Alexiadou, 1997; Cinque, 1999; Lebeaux, 1988, 1990), the structural (hierarchical) distance between the cue and the target was also greater in the non-local conditions. All three morphosyntactic conditions were matched on sentence length, and so were the local and nonlocal subconditions of each morphosyntactic condition. In each condition, all target sentences included a simple noun phrase subject (definite article+noun), a temporal adverbial (e.g., yesterday, tomorrow) (adverb phrase), an aspectual adverbial (e.g., for an hour, within an hour) (prepositional phrase), and a verb phrase consisting of a verb and an object (e.g., grilled the steaks). Therefore, all sentences (in all three morphosyntactic conditions) were precisely equated in number of phrases $(M=4)$. Moreover, the three morphosyntactic conditions did not differ significantly in number of syllables (agreement, $\mathrm{M}=17.97, \mathrm{SD}=1.55$; tense, $\mathrm{M}=$ $18.84, \mathrm{SD}=1.41$; aspect, $\mathrm{M}=19.19, \mathrm{SD}=1.70$ ) or in number of words (agreement, $\mathrm{M}=9.34, \mathrm{SD}=1.17$; tense, $\mathrm{M}=9.81, \mathrm{SD}=1.02$; aspect, $\mathrm{M}=10.03, \mathrm{SD}=0.86$ ). Likewise, there was no difference between the local and nonlocal versions of each morphosyntactic condition in number of syllables (local agreement, $\mathrm{M}=18, \mathrm{SD}=$ 1.59; nonlocal agreement, $\mathrm{M}=17.94, \mathrm{SD}=1.54$; local tense, $\mathrm{M}=18.84, \mathrm{SD}=1.42$; nonlocal tense, $\mathrm{M}=18.84, \mathrm{SD}=1.42$; local aspect, $\mathrm{M}=19.19, \mathrm{SD}=1.71$; nonlocal aspect, $\mathrm{M}=19.19, \mathrm{SD}=1.71$ ) or in number of words (local agreement, $\mathrm{M}=9.34, \mathrm{SD}$ $=1.18$; nonlocal agreement, $\mathrm{M}=9.34, \mathrm{SD}=1.18$; local tense, $\mathrm{M}=9.81, \mathrm{SD}=1.03$; nonlocal tense, $\mathrm{M}=9.81, \mathrm{SD}=1.03$; local aspect, $\mathrm{M}=10.03, \mathrm{SD}=0.86$; nonlocal aspect, $\mathrm{M}=10.03, \mathrm{SD}=0.86)$.

Local and nonlocal dependencies were pseudorandomized such that there were never more than three consecutive pairs either of the same morphosyntactic condition or of the same locality condition, and split into two lists that were administered in two 
sessions that took place with a five-day interval in between. In each session, equal numbers of nonlocal and local dependencies (evenly distributed within each morphosyntactic category) were tested. The presentation order was kept constant for all participants.

Keeping the item presentation order constant across participants is standard practice in off-line studies on aphasia (e.g., Bastiaanse et al., 2011; Faroqi-Shah \& Thompson, 2007; Kok et al., 2007; Varlokosta et al., 2006). We acknowledge that, in general, varying the item presentation order across participants is preferable to keeping the (pseudorandomized) item presentation order constant across participants, as this significantly reduces the risk of order effects. In the context of studies on aphasia, however, there is an important advantage in preserving the item presentation order across participants. In many studies on aphasia, of interest is the analysis of the results not only at the group level but also at the individual level. The analysis of the individual data sometimes reveals double dissociations, which are always interesting findings that need to be accounted for. (For an interesting discussion of the value of double dissociations, see Baddeley, 2003). Keeping the item order constant across participants ensures that, if double dissociations emerge, they are 'genuine' and cannot reflect order effects. As will be shown in the Results section, a double dissociation did emerge in the present study. Moreover, in an additional analysis of the group results, we checked for order effects (see Results).

Lastly, because of time constraints and the large number of experimental items $(\mathrm{N}=192)$ included in the sentence completion task, we did not include fillers. This is also common practice in studies on morphosyntactic production in aphasia that employ off-line tasks (e.g., Bastiaanse et al., 2011; Friedmann \& Grodzinsky, 1997; Fyndanis et al., 2012; Lee, Milman, \& Thompson, 2008; Nanousi et al., 2006; 
Protopapas, Cheimariou, Economou, Kakavoulia, \& Varlokosta, 2014; Varlokosta et al., 2006). Importantly, specific dissociations (e.g., subject-verb agreement $>$ tense) consistently emerge in agrammatic aphasia even without the inclusion of fillers in the constrained tasks employed.

\section{Procedure}

Participants were presented with the source sentence and the beginning of the target sentence auditorily and were asked to orally complete the target sentence producing the missing verb phrase. Only one repetition of the experimental pair (i.e., source sentence-beginning of target sentence) was allowed upon request by the participant. In the event of self-correction (i.e., production of more than one verb form/phrase in a given item), only the last response was retained and scored. Scoring was only based on the verb form produced by the participant. (Thus, the internal argument was ignored.) Irrelevant morphosyntactic errors were ignored. In the subject-verb agreement condition, for example, errors in tense or aspect were ignored.

\section{Results}

Individual results are shown in Table 3 . The aphasia data were analyzed at the individual level by means of Fisher's exact tests. All eight PWA showed dissociations (agreement/tense $>$ aspect, agreement $>$ tense/aspect, agreement $>$ tense $>$ aspect). While in P1, P2, P4, P5, P6, P7 and P8 dissociations between categories emerged in both local and nonlocal conditions, P3 exhibited dissociations only in the nonlocal condition. P2, P4 and P8 exhibited selective locality effects. P2 performed significantly better on local tense than on nonlocal tense (Fisher's exact test, $p=$ .011), and P4 and P8 showed the opposite pattern (in both comparisons, Fisher's exact 
test, $p<.015)$. Two control participants, C5 and C8, also exhibited selective locality effects: both of them performed significantly better on local than on nonlocal aspect (for $\mathrm{C} 5, p<.01$; for $\mathrm{C} 8, p=.011$ ), and, moreover, $\mathrm{C} 8$ also performed better on local than on nonlocal tense $(p<.05)$. Of the eight control participants, six $(\mathrm{C} 1, \mathrm{C} 2, \mathrm{C} 5$, $\mathrm{C} 6, \mathrm{C} 7, \mathrm{C} 8$ ) exhibited dissociations between the three morphosyntactic categories. C1 and $\mathrm{C} 2$ showed dissociations only in the nonlocal condition, whereas C5, C6, C7 and C8 exhibited dissociations in both local and nonlocal conditions. Interestingly, the same patterns observed within the group of PWA also emerged within the control group (agreement/tense $>$ aspect, agreement $>$ tense/aspect, agreement $>$ tense $>$ aspect).

(Insert Table 3 about here)

The group of PWA performed significantly worse on the WM tasks than the control group (Welsh t-test, $\mathrm{t}(10.665)=-4.015, p=0.002)$. At the group level, accuracy was analyzed by means of linear mixed effect regressions (Pinheiro \& Bates, 2000). Mixed models were fit by means of the Ime4 package (Bates, Maechler, Bolker, \& Walker, 2014). Initially we tried to fit generalized mixed models including both Items and Subjects as random effects and all relevant fixed effects and their interactions to the two relevant datasets. However, these models did not converge. Since the fixed effects and their interaction (see below) are theoretically relevant, we could only simplify the random structure of these models. Thus, we removed Items from the random structure, and averaged accuracy on all items per morphosyntactic category and locality condition across subjects. This way we transformed the dependent variable from dichotomous ( 0 or 1$)$ to continuous (a value ranging from 0 
to 1 , for example 0.67 ). The drawback of this approach is that the information on item variability is lost in the averaging process (Baayen, 2008); however, only this strategy allowed us to inspect the influence of the relevant variables.

The model we fitted to Dataset 1 included Morphosyntactic Condition (three levels: Agreement, Tense Aspect), Locality (two levels: Local, Nonlocal), Group (two levels: Aphasic participants, Control participants) and WM (continuous variable) as fixed effects, the interaction of all fixed effects, as well as Subjects as a random effect. The model we fitted to Dataset 2 included Morphosyntactic Condition, WM, Locality and Age as fixed effects, the interaction between Morphosyntactic Condition, WM and Locality, and Subjects as a random effect. The inclusion of Age as a covariate was motivated by the very large age range (22-86) of the 103 participants included in Dataset 2. It is well established that language and cognitive performance decline with age (Kemper, Herman, \& Lian, 2003; Kemper, Herman, \& Liu, 2004; Salthouse, 1992, 1996; Waters \& Caplan, 2005). Both models converged. Subsequently, the modelling strategy of backward elimination was adopted: starting from the initial models with the variables listed above, we excluded all variables that did not improve the goodness of fit of the model. Backward elimination was performed by means of the step function as implemented in the lmerTest package (Kuznetsova, Brockhoff, \& Christensen, 2014).

The best-fitting model for Dataset 1 included Morphosyntactic Condition and WM, the interaction of the two fixed effects, as well as Subjects as a random effect (Model 1). There was no main effect of Locality and Locality was not part of a significant interaction for any of the two datasets. Group was also not retained in the best-fitting model. The best-fitting model for Dataset 2 included Morphosyntactic Condition, WM and age as fixed factors, the interaction of Morphosyntactic 
Condition and WM, as well as Subjects as a random effect (Model 2).

Inspection of quality diagnostics for Model 1 and Model 2 yielded satisfactory results (see Supplementary Materials 2 - 6). In particular, the models showed reasonable symmetry of residuals and overall good fit of the observed data, as the scatterplots of the fitted data against the observed data (see Supplementary Materials 2 and Supplementary Materials 4) did not show relevant distortions. The partial effect of age on the 103 healthy participants (see Supplementary Materials 6) shows some heteroscedasticity in the data: as ages increases, the variance in residuals increases. This is not surprising, however, as it is expected higher variability in older individuals.

The fixed effects and interactions are reported in Table 4 and Figure 2 for Dataset 1, and in Table 5 and Figures 3 for Dataset 2. For each dataset, we report the results of the model with two reference levels: Agreement and Aspect. This enables us to compare all three categories to each other, as well as to check if WM has a differential effect on them.

(Insert Table 4 about here)

(Insert Table 5 about here)

(Insert Figure 2 about here)

(Insert Figure 3 about here) 
In both datasets, there was a main effect of Morphosyntactic Condition, with agreement eliciting a better performance than tense and aspect, and with tense eliciting a better performance than aspect. Moreover, in both datasets, there was a significant interaction between Morphosyntactic Condition and WM, with the latter affecting aspect to a greater extent than tense, and tense to a greater extent than agreement. In Dataset 2, there was also a main effect of age; the performance on the morphosyntactic task dropped with age.

Finally, in an additional analysis of the group results, to ensure that no effect of item order was present, we fitted a mixed model to Dataset 1 and Dataset 2 in which we kept the accuracy information at single trial level (dat.trial=glmer(ACC $\sim$ scale(Order.ID)+(1|Subject_ID), dath, family="binomial"). No significant effect of item order was found for either dataset.

\section{Error analysis}

In both the aphasic and healthy participants, the majority of errors were repetitiontype errors. Repetition-type errors refer to the production of verb forms that encode the same value of the relevant feature that is present in the source sentence (e.g. $1^{\text {st }} \mathrm{sg}$ in the agreement condition; XӨés mésa se mná óra eyó épsisa tis brizóles 'Yesterday within an hour I grilled-1 ${ }^{\text {st }}$.sg the steaks' (lit.) > XӨés mésa se mná óra aftós épsisa tis brizóles. 'Yesterday within an hour he grilled-1 ${ }^{\text {st }}$.sg the steaks'; PAST in the tense/time reference condition; XӨés mésa se mná óra aftós épsise tis brizóles. 'Yesterday within an hour he grilled the steaks (lit.)' > Avrio mésa se mná óra aftós épsise tis brizóles. 'Tomorrow within an hour he grilled the steaks (lit.)'; and PERFECTIVE in the Aspect condition; XӨés mésa se mná óra aftós épsise tis brizóles. 'Yesterday within an hour-perfective he grilled-perfective the steaks (lit.)'> 
XӨés epi mná óra aftós épsise tis brizóles. 'Yesterday for an hour-imperfectice he grilled-perfective the steaks (lit.)).

In the aphasic group, $86 \%(428 / 495)$ of the errors were repetition-type errors. In particular, 63\% (22/35), 79\% (132/167) and 94\% (274/293) of the agreement, tense and aspect errors, respectively, were repetition-type errors. The second most frequent error type that occurred in the tense and aspect conditions was "modality errors", that is, production of modal verb forms (e.g., $\theta$ a extiza '(I) would build (lit)') that are compatible with both past and future reference adverbials and with both perfective and imperfective aspect adverbials. Specifically, 13\% (21/167) of the errors occurred in the tense condition and 5\% (14/293) of the errors occurred in the aspect condition were modality errors. In the tense and agreement conditions, there were also substitution errors (tense condition: six present instead of past reference errors and eight present instead of future reference errors; agreement condition: seven 3rd plural instead of 3rd singular errors, two 3rd singular instead of 3rd plural errors, one 1st singular instead of 3rd singular error, and two 1st singular instead of 3rd plural errors).

In the cohort of 103 healthy participants, the vast majority of errors (98\%; $1161 / 1248)$ were repetition-type errors. Specifically, 89\% (55/62) of the agreement errors, $96 \%$ (300/312) of the tense errors, and 92\% (806/874) of the aspect errors were repetition-type errors. Other errors also included substitution and modality errors.

\section{Discussion}

This study addressed three interrelated questions:

(1) Does WM affect morphosyntactic production even in configurations that do not 
involve or favor similarity-based interference?

(2) Does WM interact with subject-verb agreement, tense/time reference, and aspect, and/or cue-target distance (locality)?

(3) Do the findings related to (1) and (2) lend support to the IFIH (Fyndanis et al., 2012)?

The results provide positive answers to all three questions. The three morphosyntactic categories under consideration were tested in configurations that did not favor or involve similarity-based interference, and two of them were affected by verbal WM. In particular, in both datasets (Dataset 1: 8 PWA and 8 healthy controls; Dataset 2: 103 healthy individuals), a limited WM capacity affected tense and aspect, but not subject-verb agreement, and limited WM capacity affected aspect more than tense. There was no effect of locality or an interaction of other factors with locality. These results suggest that processing aspect and tense tax the WM system regardless of whether the verb is distant from the aspectual or temporal adverbial. It is the inherent properties of these categories that render them demanding in terms of processing resources.

The pattern of dissociation between subject-verb agreement, tense, and aspect (subject-verb agreement $>$ tense $>$ aspect) and the interaction of WM with these morphosyntactic categories is consistent with the IFIH (Fyndanis et al., 2012), according to which PWA have difficulty processing and integrating information from two distinct levels of representation, namely grammatical and conceptual/extralinguistic (Fyndanis et al., 2012). Aspect and tense involve integration processes whereas subject-verb agreement does not. Moreover, our results lend empirical support to Fyndanis et al.'s $(2012,2013)$ claim that, at least in Greek, aspect is more demanding than tense in terms of processing resources. As suggested 
by Fyndanis et al. (2013), aspect could be more demanding than tense in terms of processing resources due to its subjectivity (e.g., Comrie, 1976; Smith, 1997; see also Fyndanis et al., 2013: 181). A speaker of Greek, for example, often chooses how to view an event; in a perfective or in an imperfective way. In contrast to aspect, the decision of the speaker to refer to the past, to the present or to the future is based on more objective criteria (i.e., location of the event time in relation to the utterance time). Although constrained tasks employed to investigate aspect usually include adverbials that call for specific aspectual values (which is the case in the present study), it might be the case that the subjective component of aspectual representations is always "active", rendering the decoding and encoding of aspect more costly than the decoding and encoding of tense, which has an impact on its production (i.e. lower accuracy rates compared to tense). (Note the in sentence completion tasks the participant has to both decode the relevant features during the listening/ comprehension part and to encoding them during the production part.)

An anonymous reviewer observed that "there are multiple findings from English-speaking PWA suggesting that aspectual morphology (especially progressive) is relatively unimpaired" (e.g., Druks \& Carroll, 2005; Milman, Dickey, \& Thompson, 2008). Certainly, based on the observed discrepancy in aspect production between Greek aphasia (e.g., Fyndanis et al., 2012; Nanousi et al., 2006; Varlokosta et al., 2006, present study) and English aphasia (e.g., Milman et al., 2008), one could argue that there are cross-linguistic differences in the degree of impairment in aspect, and that these differences may result from language-specific properties of aspect. If this is the case, it seems that the processing load of a given morphosyntactic category does not only depend on the involvement of integration processes (IFIH; Fyndanis et al., 2012) but also on language-specific properties of this category (see also Fyndanis 
et al., 2017). This possibility cannot be ruled out. However, the findings that aspect is well-preserved is English aphasia should be treated with caution. This is so because the English findings on aspect were based either on analysis of spontaneous speech (e.g., Milman, Dickey, \& Thompson, 2008) or on constrained tasks that failed to tease apart tense from aspect (e.g., Druks \& Carroll, 2005). Analysis of spontaneous speech is a suboptimal method because all finite verb forms in languages such as Greek and English bear an aspectual value (e.g., imperfective/progressive or perfective/nonprogressive). Hence, whenever the participant produces a finite verb, (s)he produces aspectual morphology. In spontaneous speech, however, and given the subjectivity of aspect (Comrie, 1976; Smith, 1997), it is difficult for the experimenter to infer what the intended aspectual value is. This is especially true when the participant does not produce aspectual adverbials that restrict the aspectual value encoded in the verb, which is often the case. Aspect could be tested reliably by means of constrained tasks that include as cues aspectual adverbials that are compatible with only one aspectual value. (In Greek, for example, the aspectual adverbial epí mná óra 'for an hour' is compatible with imperfective aspect only, and the aspectual adverbial mésa se mná óra 'within an hour' is compatible with perfective aspect only.) Specifically, these constrained tasks should include pairs of aspectual adverbials that elicit two different aspectual values (e.g., perfective and imperfective aspect) keeping the time frame constant (see, for example, sentence completion task in the present study). This kind of tasks allow us to tease apart aspect from tense/time reference while considering the encoding and retrieval components of aspect to a similar extent. (In this context, the encoding component is responsible for specifying ("encoding") the abstract, prephonological aspectual value (e.g., PERFECTIVE), and the retrieval component is responsible for retrieving the corresponding verb forms/inflections; see Faroqi-Shah 
\& Thompson, 2007, and references therein).) The bulk of Greek findings on aspect were based on constrained tasks that met the above criteria (see, for example, Fyndanis et al., 2012; Protopapas et al., 2014; Varlokosta et al., 2006, and present study).

The finding that WM is critically involved in morphosyntactic production even in configurations that do not involve similarity-based interference is consistent with previous findings from aphasia (e.g., Kok et al., 2007), and sheds more light on the role of WM in grammatical encoding/morphosyntactic production. This finding is also in line with psycholinguistic studies that provide evidence for an important role of WM in morphosyntactic production (e.g., Badecker \& Kuminiak, 2007; Hartsuiker \& Barkhuysen, 2006; Slevc \& Martin, 2016), and at odds with the view that the processes involved in grammatical encoding (e.g., verb retrieval) are largely automatic (e.g., Levelt, 1989).

The identical pattern of performance exhibited by the aphasic group and the large group of healthy speakers (agreement $>$ tense $>$ aspect) is consistent with the idea that, at least in morphosyntactic production, the performance of PWA and neurologically intact speakers differs quantitatively and not qualitatively (Dick et al., 2001; Miyake et al., 1994). The fact that Group was not retained in the best-fitting model does not mean that the aphasic group and the control group had a similar level of performance. In one of the initial models we fitted, which did not include WM (ACC $\sim$ Condition*Locality+Group $+(1 \mid$ Subject_ID $)+(1 \mid$ Items $), \quad$ dat, family="binomial"), there was a main effect of Group, with PWA performing worse than control participants. Group was not retained in the best-fitting model because, when including WM as a covariate, the effect of Group disappeared. Taken together, 
the outputs of these two models suggest that the PWA group and the control group are different, and that this difference can be reduced to WM differences.

Turning to the effect of WM, we first note the concept of WM-and the means whereby it is tested-includes the functions of maintenance of item and order information and manipulation of this information in the service of a task. Baddeley and his colleagues (e.g., Baddeley \& Hitch, 1974) emphasized the functions of maintenance of item-and-order information and processing, and Engle and his colleagues emphasized task maintenance and suppression of erroneous pre-potent responses, an important function of WM (see also Cowan's (2017) idea of “Inclusive WM" based on Unsworth and Engle, 2007). We suggest that the WM effect in this task is due to the processing and control functions of WM.

Attentional control, storage and processing are required in all three conditions (subject-verb agreement, tense, aspect) of the production task. Attentional control is needed to inhibit (or suppress) the non-target value of the relevant feature encoded in the verb form that appeared in the source sentence. For instance, in the tense condition, the relevant feature is Tense/Time Reference and its values are PAST and FUTURE. One of these two values are encoded in the verb form that appears in the source sentence. The participant has to inhibit a response that encodes the same value. This is a feature of this task, and would not necessarily be found in other sentence production settings. Storage is needed to maintain the lemma representation of the verb appeared in the source sentence and the values of the grammatical features carried by the preverbal material (person value, number value, time reference value, and aspect value) in the target sentence. Processing is needed for both encoding the values of the agreement-, tense/time reference- and aspect-related grammatical features and retrieving the corresponding verb forms/inflections from long-term 
memory. The processing load was heavier for tense and aspect than for subject-verb agreement, since the former categories require integration of information from two distinct levels or representation (extra-linguistic/conceptual and grammatical), as discussed above.

The fact that the performance on aspect and tense was significantly worse than that on subject-verb agreement, coupled with the fact that most of the errors occurred were repetition-type errors (i.e. repetition of the non-target value of the relevant feature encoded in the verb form appearing in the source sentence), suggests that control and processing functions of WM are responsible for its role. The absence of an effect of locality and the fact that the effect of WM was independent of locality suggests that the aspect of WM that is relevant to the processing of tense and aspect is not maintenance of item or item-and-order information.

At the individual level, high variability was observed across PWA, as three distinct patterns of performance emerged (agreement $>$ tense/aspect, agreement $>$ tense $>$ aspect, agreement/tense $>$ aspect). The observed variation across subjects is consistent with Kolk's (2007) claim that "Variability is the hallmark of aphasic behavior: Grammatical behaviour is no exception" (p. 99). Despite the variability, however, only one of the eight PWA, P5, exhibited a pattern (agreement/tense > aspect) that is not consistent with the IFIH (Fyndanis et al., 2012). This is consistent with the conclusions drawn on the basis of the group results. Interestingly, the same patterns of performance were exhibited by the control participants. Thus, variability seems to characterize the morphosyntactic production behavior of both PWA and healthy speakers. We should note, however, that, in studies that do not employ sensitive behavioral measures (e.g., reaction times), this variability is more likely to emerge in healthy older speakers. In the present study, the younger participants 
included in the large cohort of healthy participants performed at ceiling on all three morphosyntactic categories. This was not the case with the older healthy participants (see Supplementary Materials 7).

An anonymous reviewer raised the alternative possibilities that the different patterns of performance across PWA can be related to properties of these participants, or are simply random. The fact that both PWA and healthy participants exhibited the same variety of patterns at the individual level, coupled with the fact that PWA and healthy participants yielded the same pattern at the group level, suggests that the "individual departures" from the dominant pattern are random.

A locality effect emerged only at the individual level for the PWA and control participants. Interestingly, a double dissociation emerged in the tense condition within the group of PWA: P2 performed better on local than on nonlocal tense, but P4 and P8 performed better on nonlocal than on local tense. Based on Fyndanis et al.'s (2014) findings, the antilocality effect exhibited by P4 and P8 was not expected and remains to be explained. It may be that locality effects emerged in configurations that do not favor or allow similarity-based interference are due to time-based decay of representations in WM (e.g, Barrouillet \& Camos, 2012), and antilocality effects are due to intermittent dysfunction of the focus of attention. According to McElree (2006) the focus of attention can only hold up one item or chunk, and specifically the most recent one. This result suggests that, at least for some PWA, locality matters. Thus, experimental designs aiming at testing morphosyntactic phenomena should take this variable into consideration, because otherwise a potential confound is introduced, which can give rise to artifacts. In fact, some of the dissociations between morphosyntactic categories reported in the aphasia literature may be artifacts of experimental designs involving such confounds (see, for example, Fyndanis et al., 
2012; Gavarrò \& Martínez-Ferreiro, 2007; Nanousi et al., 2006; Varlokosta et al., 2006).

To summarize, the results suggest that verbal WM can affect aspects of morphosyntactic production, even in configurations that do not involve similaritybased interference. We also found an interaction between morphosyntactic categories and verbal WM, with the latter affecting tense and aspect but not subject-verb agreement. This is consistent with the IFIH (Fyndanis et al., 2012). The results suggest that the activation of conceptual information, mapping that information onto prephonological morphosyntactic features, and/or retrieving the corresponding verb forms is demanding. We found no effect of the distance between the cue and the target, or an interaction of locality and WM at the group level. This suggests that the aspect of WM that supports morphosyntactic production is its role in processing information and/or, in this task, suppressing responses based on previously presented information.

The results also have clinical implications. We found that WM plays an important role in morphosyntactic production, suggesting that WM/cognitive training should lead to improvement of production abilities, at least in the domain of verbrelated morphosyntax. To our knowledge, only the effects of cognitive training on sentence comprehension have been explored thus far, with promising results (e.g., Salis, 2012; Zakariás, Keresztes, Marton, \& Wartenburger, 2016). Future research, thus, should explore the effects of cognitive training on verb-related morphosyntactic production. Another clinical implication is that non-cognitive treatment provided to agrammatic speakers should target verb-related morphosyntactic production, and especially so categories at the interface between morphosyntax and semantics, such as tense/time reference and aspect. 
Concluding, we should acknowledge some limitations of the study and identify issues that should be addressed in future research. First of all, the aphasic group consisted of a relatively small number of PWA $(\mathrm{N}=8)$. Future studies should try to replicate our results with a considerably larger cohort of PWA. Second, our claim that the impaired morphosyntactic production in agrammatic aphasia stems from a deficit in the processing and control functions of WM and not from storage limitations is only based on indirect evidence (i.e., absence of a locality effect at the group level and qualitative aspects of performance based on error analysis). A follow-up study should include measures not only of WM but also of short-term memory and inhibition/control in order to test the above hypothesis in a straightforward way. Future research should also explore the role of other variables that might play a role in morphosyntactic production. Education, for example, as pointed out by Simos, Kasselimis, and Mouzaki (2011, p. 487), "may directly affect performance on verbal tests $[\ldots]$, as a proxy for higher professional attainment, further formal linguistic experience, and cognitive reserve, and also as an indicator of increased experience in formal testing situations (Ostrosky-Solis, Ardila, Roselli, Lope-Arango, \& UrielMendoza, 1998)". Thus, future research should address whether education interacts with verbal WM capacity, cognitive control/inhibition and morphosyntactic processing in production. 


\section{Acknowledgments}

This research was supported by a Marie Curie Intra European Fellowship (awarded to the first author) within the $7^{\text {th }}$ European Community Framework Programme, project reference 329795, and by the Research Council of Norway through its Centres of Excellence funding scheme, project number 223265.

We are grateful to all individuals who took part in this study. We also thank Pola Drakopoulou, Irene Choudala and Eva-Maria Tsapakis for contributing to data collection, Fabiana Galiussi for helping with data transcription and analysis, and Artemis Alexiadou, Frank Burchert, Kleanthes Grohmann, Michaela Nerantzini, Neal Pearlmutter, Charalambos Themistokleous, Maria Varkanitsa, Spyridoula Varlokosta, and Isabell Wartenburger for their useful suggestions and comments. Last but not least, many thanks go to the audiences of the following conferences, workshops, and seminars, where earlier versions of this work were presented: 51st Academy of Aphasia Annual Meeting (Lucerne, Switzerland), 31st European Workshop on Cognitive Neuropsychology (Bressanone, Italy), 11th International Conference on Greek Linguistics (Rhodes, Greece), Mind, Brain \& Body Symposium (Berlin, Germany), $5^{\text {th }}$ Conference on Language Disorders (Limassol, Cyprus), European Master in Clinical Linguistics guest speaker seminar (Department of Linguistics, University of Potsdam, Germany), Neurolinguistics Colloquium (Department of Linguistics, University of Potsdam, Germany). 


\section{References}

Alexiadou, A. (1997). Adverb placement: A case study in antisymmetric syntax. Amsterdam: John Benjamins.

Almor, A., MacDonald, M. C., Kempler, D., Andersen, E. S., \& Tyler, L. K. (2001). Comprehension of long distance number agreement in probable Alzheimer's disease. Language and Cognitive Processes, 16, 35-63.

Baayen, R. H. (2008). Analyzing linguistic data: A practical introduction to statistics using R. Cambridge University Press.

Badecker, W., \& Kuminiak, F. (2007). Morphology, agreement and working memory retrieval in sentence production: Evidence from gender and case in Slovak. Journal of Memory and Language, 56, 65-85.

Baddeley, A. (2003). Double dissociations: Not magic but still useful. Cortex: A Journal Devoted to the Study of the Nervous System and Behavior, 39, 129-131.

Baddeley, A. \& Hitch, G. (1974). Working Memory. Psychology of Learning and Motivation Advances in Research and Theory, 8, 47-89.

Barrouillet, P. \& Camos, V. (2012). As time goes by: Temporal constraints in working memory. Current Directions in Psychological Science, 21, 413-419.

Bates, D., Maechler, M., Bolker, B., \& Walker, S. (2014). lme4: Linear mixedeffects models using Eigen and S4. R package version 1.1-6. http://CRAN.Rproject.org/package $=1 \mathrm{lme} 4$

Baum, S. R. (1989). On-line sensitivity to local and long-distance syntactic dependencies in Broca's aphasia. Brain and Language, 37, 327-338.

Bock, J. K., \& Cutting, J. C. (1992). Regulating mental energy: Performance units in language production. Journal of Memory and Language, 31, 99-127.

Bock, K., Loebell, H., \& Morey, R. (1992). From conceptual roles to structural 
relations: Bridging the syntactic cleft. Psychological Review, 99, 150-171.

Bock, K., \& Miller, C. A. (1991). Broken agreement. Cognitive Psychology, 23, 4593.

Caplan, D., \& Waters, G. S. (1995). Aphasic disorders of syntactic comprehension and working memory capacity. Cognitive Neuropsychology, 12, 637-649.

Caplan, D., \& Waters, G. S. (1999). Verbal working memory and sentence comprehension. Behavioral and Brain Sciences, 22, 77-126.

Caplan, D., \& Waters, G. (2013). Memory mechanisms supporting syntactic comprehension. Psychonomic Bulletin and Review, 20, 243-268.

Caplan, D., \& Hildebrandt, N. (1988). Disorders of syntactic comprehension. Cambridge, MA: MIT Press.

Chomsky, N. (1995). The Minimalist Program. Cambridge, MA: MIT Press.

Chomsky, N. (2000). Minimalist inquiries: The framework. In R. Martin, D.

Michaels, \& J. Uriagereka (Eds.), Step by Step (pp. 89-155). Cambridge, MA: MIT

Press.

Chomsky, N. (2001). Derivation by phase. In K. Kenstowicz (Ed.), Ken Hale: A Life in Language (pp. 1-52). Cambridge, MA: MIT Press.

Cinque, G. (1999). Adverbs and functional heads: A cross-linguistic perspective. Oxford: Oxford University Press.

Comrie, B. (1976). Aspect. New York, NY: Cambridge University Press.

Cowan, N. (2017). The many faces of working memory and short-term storage. Psychonomic Bulletin \& Review, 24, 1158-1170.

Dick, F., Bates, E., Wulfeck, B., Utman, J. A., Dronkers, N., \& Gernsbacher, M. A. (2001). Language deficits, localization, and grammar: Evidence for a distributive model of language breakdown in aphasic patients and neurologically intact 
individuals. Psychological Review, 108, 759-788.

Druks, J., \& Carroll, E. (2005). The crucial role of tense for verb production. Brain and Language, 94, 1-18.

Faroqi-Shah, Y., \& Thompson, C. K. (2004). Semantic, lexical, and phonological influences on the production of verb inflections in agrammatic aphasia. Brain and Language, 89, 484-498.

Faroqi-Shah, Y., \& Thompson, C. K. (2007). Verb inflections in agrammatic aphasia: Encoding of tense features. Journal of Memory and Language, 56, 129-151. Ferreira, V. S., \& Pashler, H. (2002). Central bottleneck influences on the processing stages of word production. Journal of Experimental Psychology: Learning, Memory, and Cognition, 28, 1187-1199.

Ferreira, V. S., \& Slevc, L. R. (2007). Grammatical encoding. In M. G. Gaskell (Ed.), The Oxford handbook of psycholinguistics (pp. 453-469). Oxford, England: Oxford University Press.

Folstein, M., Folstein, S., \& McHugh, P. R. (1975). Mini Mental State: A practical method for grading the cognitive state of patients for the clinician. Journal of Psychiatric Research, 12, 189-198.

Fountoulakis, K. N., Tsolaki, M., Chantzi, H., \& Kazis, A. (2000). Mini Mental State Examination (MMSE): A validation study in Greece. American Journal of Alzheimer's Disease and Other Dementias, 15, 342-345.

Francis, D. R., Clark, N., \& Humphreys, G. W. (2003). The treatment of an auditory working memory deficit and the implications for sentence comprehension abilities in mild 'receptive' aphasia. Aphasiology, 17, 723-750.

Friedmann, N., \& Grodzinsky, Y. (1997). Tense and agreement in agrammatic production: Pruning the syntactic tree. Brain and Language, 56, 397-425. 
Friedmann, N., \& Gvion, A. (2003). Sentence comprehension and working memory limitation in aphasia: A dissociation between semantic-syntactic and phonological reactivation. Brain and Language, 86, 23-39.

Fyndanis, V., Arfani, D., Varlokosta, S., Burgio, F., Maculan, A., Miceli, G., Arcara, G., Palla, F., Cagnin, A., Papageorgiou, S., \& Semenza, C. (2017). Morphosyntactic production in Greek- and Italian-speaking individuals with probable Alzheimer's disease: Evidence from subject-verb agreement, tense/time reference, and mood. Aphasiology. DOI: 10.1080/02687038.2017.1358352

Fyndanis, V., Galiussi, F., \& Christidou, P. (2014). A database of Greek-speaking neurologically healthy individuals' (semi)spontaneous speech. Unpublished database.

Fyndanis, V., Manouilidou, C., Koufou, E., Karampekios, S., \& Tsapakis, E. M. (2013). Agrammatic patterns in Alzheimer's disease: Evidence from tense, agreement, and aspect. Aphasiology, 27, 178-200.

Fyndanis, V., Nerantzini, M., Choudala, I., \& Tsapakis, E. M. (2014). Production of functional categories in agrammatic aphasia and task-related processing demands: The role of \pm distant cues. In G. Kotzoglou et al. (Eds), Selected Papers of the $11^{\text {th }}$ International Conference on Greek Linguistics (pp. 428-438). Rhodes/Greece: University of the Aegean.

Fyndanis, V., Varlokosta, S., \& Tsapkini, K. (2012). Agrammatic production: Interpretable features and selective impairment in verb inflection. Lingua, 122, 1134 1147.

Garrett, M. F. (1982). Production of speech: Observations from normal and pathological language use. In A. W. Ellis (Ed.), Normality and pathology in cognitive functions (pp. 19-76). London: Academic Press.

Gavarrò, A., \& Martínez-Ferreiro, S. (2007). Tense and agreement impairment in 
Ibero-Romance. Journal of Psycholinguistic Research, 36, 25-46.

Gibson, E. (1998). Linguistic complexity: Locality of syntactic dependencies. Cognition, 68, 1-76.

Gibson, E. (2000). The dependency locality theory: A distance-based theory of linguistic complexity. In Y. Miyashita, A. Marantz, \& W. O'Neil (Eds.), Image, language, brain (pp. 95-126). Cambridge, MA: MIT Press.

Goodglass, H., Kaplan, E., \& Barresi, B. (2001). Boston Diagnostic Aphasia Examination: Short Form Record Booklet (3rd ed). Boston, MA: Lippincott Williams and Wilkins.

Goodglass, H., Kaplan, E., \& Baressi B. (2013). The Assessment of Aphasia and related disorders: Adaptation and Validation of the Boston Diagnostic Aphasia Examination-Short Form in Greek. [Eds: L. Messinis, A. Kastellakis, E. Panagea, \& P. Papathanasopoulos.] Patra: Gotsis. (in Greek)

Just, M. A., \& Carpenter, P. A. (1992). A capacity theory of comprehension: Individual differences in working memory. Psychological Review, 99, 122-149.

Haarmann, H. J., Just, M. A., \& Carpenter, P. A. (1997). Aphasic sentence comprehension as a resource deficit: A computational approach. Brain and Language, $59,76-120$.

Hartsuiker, R. J., \& Barkhuysen, P. N. (2006). Language production and working memory: The case of subject-verb agreement. Language and Cognitive Processes, 21, $181-204$.

Holton, D., Mackridge, P., \& Philippaki-Warburton, I. (1997). Greek: A Comprehensive Grammar of the Modern Language. London/New York: Routledge. Humphreys, K. R., \& Bock, K. (2005). Notional number agreement in English. Psychonomic Bulletin \& Review, 12, 689-695. 
Kemper, S., Herman, R., \& Lian, C. (2003). Age differences in sentence production. Journal of Gerontology: Psychological Sciences, 58B, P260-P268.

Kemper, S., Herman, R. E., \& Liu, C.-J. (2004). Sentence production by young and older adults in controlled contexts. Journal of Gerontology: Psychological Sciences, 59B, P220-P224.

King, J., \& Just, M. A. (1991). Individual differences in syntactic processing: The role of working memory. Journal of Memory and Language, 30, 580-602.

Kok, P., van Doorn, A., \& Kolk, H. (2007). Inflection and computational load in agrammatic speech. Brain and Language, 102, 273-283.

Kolk, H. (2007). Variability is the hallmark of aphasic behaviour: Grammatical behaviour is no exception. Brain and Language, 101, 99-102.

Kolk, H. H. J., Chwilla, D. J., van Herten, M., \& Oor, P. J. W. (2003). Structure and limited capacity in verbal working memory: A study with event-related potentials. Brain and Language, 85, 1-36.

Kuznetsova, A., Brockhoff, P. B., \& Christensen, R. H. B. (2014). lmerTest: Tests for random and fixed effects for linear mixed effect models (lmer objects of lme4 package). R package version 2.0-6. http://CRAN.R-project.org/package=lmerTest

Lebeaux, D. (1988). Language acquisition and the form of the grammar. $\mathrm{PhD}$ dissertation, University of Massachusetts, Amherst.

Lebeaux, D. (1990). Relative clauses, licensing, and the nature of the derivation. In Proceedings of NELS 20 (pp. 318-332). Amherst: Graduate Linguistic Student Association.

Lee, J., Milman, L. H., \& Thompson, C. K. (2008). Functional category production in English agrammatism. Aphasiology, 22, 893-905.

Levelt, W. J. M. (1989). Speaking: From intention to articulation. Cambridge, MA: 
MIT Press.

Levelt, W. J. M. (1999). Producing spoken language: A blueprint of the speaker. In C. M. Brown, \& P. Hagoort (Eds.), The Neurocognition of Language (pp. 83-122). New York: Oxford University Press.

Love, T., \& Swinney, D. (1996). Co-reference processing and levels of analysis in object-relative constructions: Demonstration of antecedent reactivation with the crossmodal priming paradigm. Journal of Psycholinguistic Research, 25, 5-24.

Lukatela, K., Shankweiler, D., \& Crain, S. (1995). Syntactic processing in agrammatic aphasia by speakers of a Slavic language. Brain and Language, 49, 5076.

MacDonald, M. C., Almor, A., Henderson, V. W., Kempler, D., \& Andersen, E. S. (2001). Assessing working memory and language comprehension in Alzheimer's disease. Brain and Language, 78, 17-42.

MacDonald, M. C., \& Christiansen, M. H. (2002). Reassessing working memory: Comment on Just and Carpenter (1992) and Waters and Caplan (1996). Psychological Review, 109, 35-54.

Martin, R. C., \& Freedman, M. L. (2001). Relations between language and memory deficits. In R. S. Berndt (Ed.), Handbook of Neuropsychology (2nd edition, Vol. 3) (pp. 239-256). Amsterdam: Elsevier.

Martin, R. C., \& Sleve, L. R. (2014). Language production and working memory. In M. Goldrick, V. S. Ferreira, \& M. Miozzo (Eds.), The Oxford Handbook of Language Production (pp. 120-131). Oxford University Press.

Mayer, J. F., \& Murray, L. L. (2002). Approaches to the treatment of alexia in chronic aphasia. Aphasiology, 16, 727-743.

McElree, B. (2000). Sentence comprehension is mediated by content-addressable 
memory structures. Journal of Psycholinguistic Research, 29, 111-123.

McElree, B. (2006). Accessing recent events. In B. H. Ross (Ed.), The Psychology of Learning and Motivation (Vol. 46, pp. 155-200).Elree San Diego, CA: Academic Press.

Milman, L. H., Dickey, M. W., \& Thompson, C. K. (2008). A psychometric analysis of functional category production in English agrammatic narratives. Brain and Language, 105, 18-31.

Miyake, A., Carpenter, P. A., \& Just, M. (1994). A capacity approach to syntactic comprehension disorders: Making normal adults perform like aphasic patients. Cognitive Neuropsychology, 11, 671-717.

Murray, L. L., Keeton, R. J., \& Karcher, L. (2006). Treating attention in mild aphasia: Evaluation of attention process training-II. Journal of Communication Disorders, 39, 37-61.

Nanousi, V., Masterson, J., Druks, J., \& Atkinson, M. (2006). Interpretable vs. uninterpretable features: Evidence from six Greek-speaking agrammatic patients. Journal of Neurolinguistics, 19, 209-238.

Ness, T., \& Meltzer-Asscher, A. (2017). Working memory in the processing of longdistance dependencies: Interference and filler maintenance. Journal of Psycholinguistic Research. DOI: 10.1007/s10936-017-9499-6

Nittrouer, S., Lowenstein, J. H., Wucinich, T., \& Moberly, A. C. (2016). Verbal Working Memory in older adults: The roles of phonological capacities and processing speed. Journal of Speech, Language, and Hearing Research, 59, 1520-1532.

Ostrosky-Solis, F., Ardila, A., Roselli, M., Lope-Arango, G., \& Uriel-Mendoza, V. (1998). Neuropsychological test performance in illiterate subjects. Archives of Clinical Neuropsychology, 13, 645-660. 
Pickering, M. J., \& Garrod, S. (2013). An integrated theory of language production and comprehension. Behavioral and Brain Sciences, 36, 329-392.

Pinheiro, J. C., \& Bates, D. M. (2000). Mixed-effects models in S and S-PLUS, Statistics and Computing. New York: Springer.

Potagas, C., Kasselimis, D., \& Evdokimidis, I. (2011). Short-term and working memory impairments in aphasia. Neuropsychologia, 49, 2874-2878.

\section{Protopapas, A., Cheimariou, S., Economou, A., Kakavoulia, M., \& Varlokosta, S.} (2014). Functional categories related to verb inflection are not differentially impaired in Greek aphasia. Language and Cognition, 8, 124-141.

Roberts, R., \& Gibson, E. (2002). Individual differences in sentence memory. Journal of Psycholinguistic Research, 31, 573-598.

Salis, C. (2012). Short-term memory treatment: Patterns of learning and generalisation to sentence comprehension in a person with aphasia. Neuropsychological Rehabilitation, 22, 428-448.

Zakariás, L., Keresztes, A., Marton, K., \& Wartenburger, I. (2016). Positive effects of a computerized working memory and executive function training on sentence comprehension in aphasia. Neuropsychological Rehabilitation.

DOI: $10.1080 / 09602011.2016 .1159579$

Salis, C., Kelly, H., \& Code, C. (2015). Assessment and treatment of short-term and working memory impairments in stroke aphasia: A practical tutorial. International Journal of Language and Communication Disorders, 50, 721-736.

Salthouse, T. A. (1992). Mechanisms of age-cognition relations in adulthood. Hillsdale, N.J.: Erlbaum.

Salthouse, T. A. (1996). The processing-speed theory of adult age differences in cognition. Psychological Review, 103, 403-428. 
Simos, P. G., Kasselimis, D., \& Mouzaki, A. (2011). Age, gender, and education effects on vocabulary measures in Greek. Aphasiology, 25, 475-491.

Slevc, L. R., \& Martin, R. C. (2016). Syntactic agreement attraction reflects working memory processes. Journal of Cognitive Psychology, 28, 773-790.

Smith, C. S. (1997). The parameter of aspect (2nd ed.). Dordrecht: Kluwer Academic Publishers.

Smith, M., \& Wheeldon, L. (2001). Syntactic priming in spoken sentence production: An online study. Cognition, 78, 123-164.

Solomon, E. S., \& Pearlmutter, N. J. (2004). Semantic integration and syntactic planning in language production. Cognitive Psychology, 49, 1-46.

Sung, J. E. (2009). The effects of locality on sentence comprehension in persons with aphasia and normal individuals. Doctoral dissertation, available on-line: http://dscholarship.pitt.edu/6259/1/SUNG_ETD.pdf. University of Pittsburgh.

Sung, J. E. (2015). Age-related changes in sentence production abilities and their relation to working memory capacity: Evidence from a verb-final language. PLoS ONE, 10(4): e0119424.

Thompson, C. K., Shapiro, L. P., Tait, M. E., Jacobs, B. J., Schneider, S. L., \& Ballard, K. J. (1995). A system for the linguistic analysis of agrammatic language production. Brain and Language, 51, 124-127.

Unsworth, N., \& Engle, R. W. (2007). The nature of individual differences in working memory capacity: Active maintenance in primary memory and controlled search from secondary memory. Psychological Review, 114, 104-132.

Varlokosta, S., Valeonti, N., Kakavoulia, M., Lazaridou, M., Economou, A., \& Protopapas, A. (2006). The breakdown of functional categories in Greek aphasia: Evidence from agreement, tense, and aspect. Aphasiology, 20, 723-743. 
Waters, G. S., \& Caplan, D. (2002). Working memory and on-line syntactic processing in Alzheimer's disease: Studies with auditory moving windows presentation. Journal of Gerontology: Psychological Sciences, 57B, 298-311.

Waters, G. S., \& Caplan, D. (2003). The reliability and stability of verbal working memory measures. Behavior Research Methods, Instruments, \& Computers, 35, 550564.

Waters, G. S., \& Caplan, D. (2005). The relationship between age, processing speed, working memory capacity, and language comprehension. Memory, 13, 403-413.

Wechsler, D. (2008). Wechsler Adult Intelligence Scale - Fourth Edition (WAIS-IV). San Antonio, Texas: NCS Pearson. 
Figure 1. Distribution of participants across lifespan decades. The x-axis represents the age range taken into account, separated in bins. The height of the columns in the $\mathrm{y}$-axis is proportional to the number of observations for the age bin.

Figure 2. The plot depicts the significant interaction between Morphosyntactic Condition and WM of Model 1 fitted to Dataset 1 ( 8 aphasic and 8 control participants). The plot shows that the more limited the verbal WM capacity, the larger the difference between the three morphosyntactic categories. WM did not affect subject-verb agreement, but did affect aspect and -to a lesser extent- tense.

Figure 3. The plot depicts the significant interaction between Morphosyntactic Condition and WM of Model 2 fitted to Dataset 2 (103 healthy participants). The plot shows that the more limited the verbal WM capacity, the larger the difference between the three morphosyntactic categories. WM did not affect subject-verb agreement, but did affect aspect and -to a lesser extent- tense. 


\section{Supplementary Materials}

Supplementary Materials 1 . Scale profile of PWA's speech characteristics.

Supplementary Materials 2. Diagnostics for Model 1.

Supplementary Materials 3. Partial residuals for WM in Model 1.

Supplementary Materials 4. Diagnostics for Model 2.

Supplementary Materials 5. Partial residuals for WM in Model 2.

Supplementary Materials 6. Partial residuals for age in Model 2.

Supplementary Materials 7. Individual performance (correct) of healthy participants on subject-verb agreement, tense, and aspect (with local and nonlocal conditions collapsed).

\footnotetext{
${ }^{\mathrm{i}}$ Based on Love and Swinney (1996), who have shown that in sentences with objectextracted relative clauses the activation at the gap is semantic rather than phonological in nature (a view shared by Martin and Freedman (2001) and Friedmann and Gvion (2003), among others), we assume that, likewise, reactivation of lexico-
} 
2

semantic (and not of phonological) information is required at the point when participants have to produce the verb in sentence completion tasks examining morphosyntactic or morphosemantic phenomena, such as agreement, tense and aspect. This means that it is the number of intervening features, not the number of syllables or words, that is the optimal metric of distance. 
Table 1. Aphasic and control participants' demographic and selected language testing data.

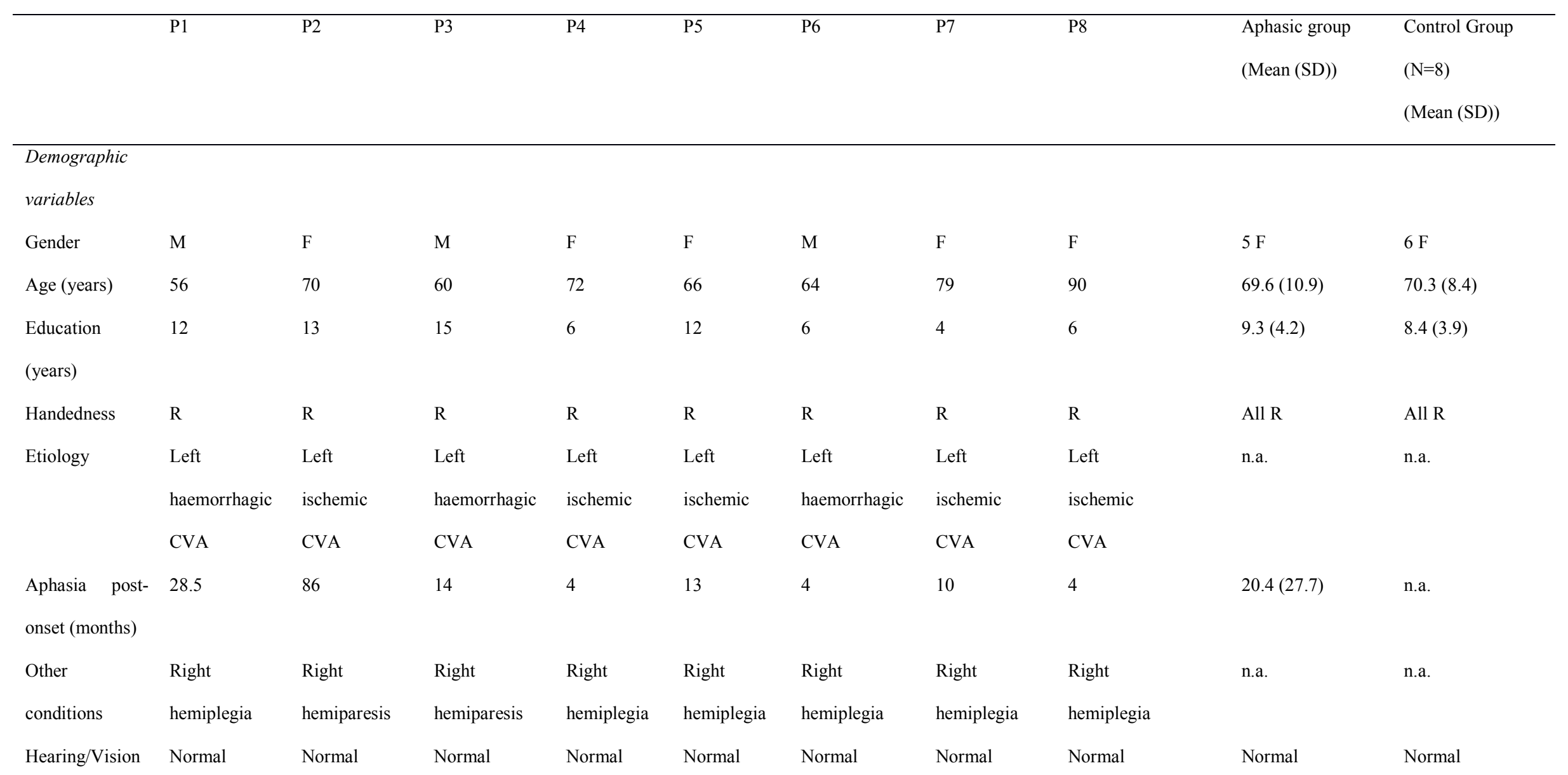




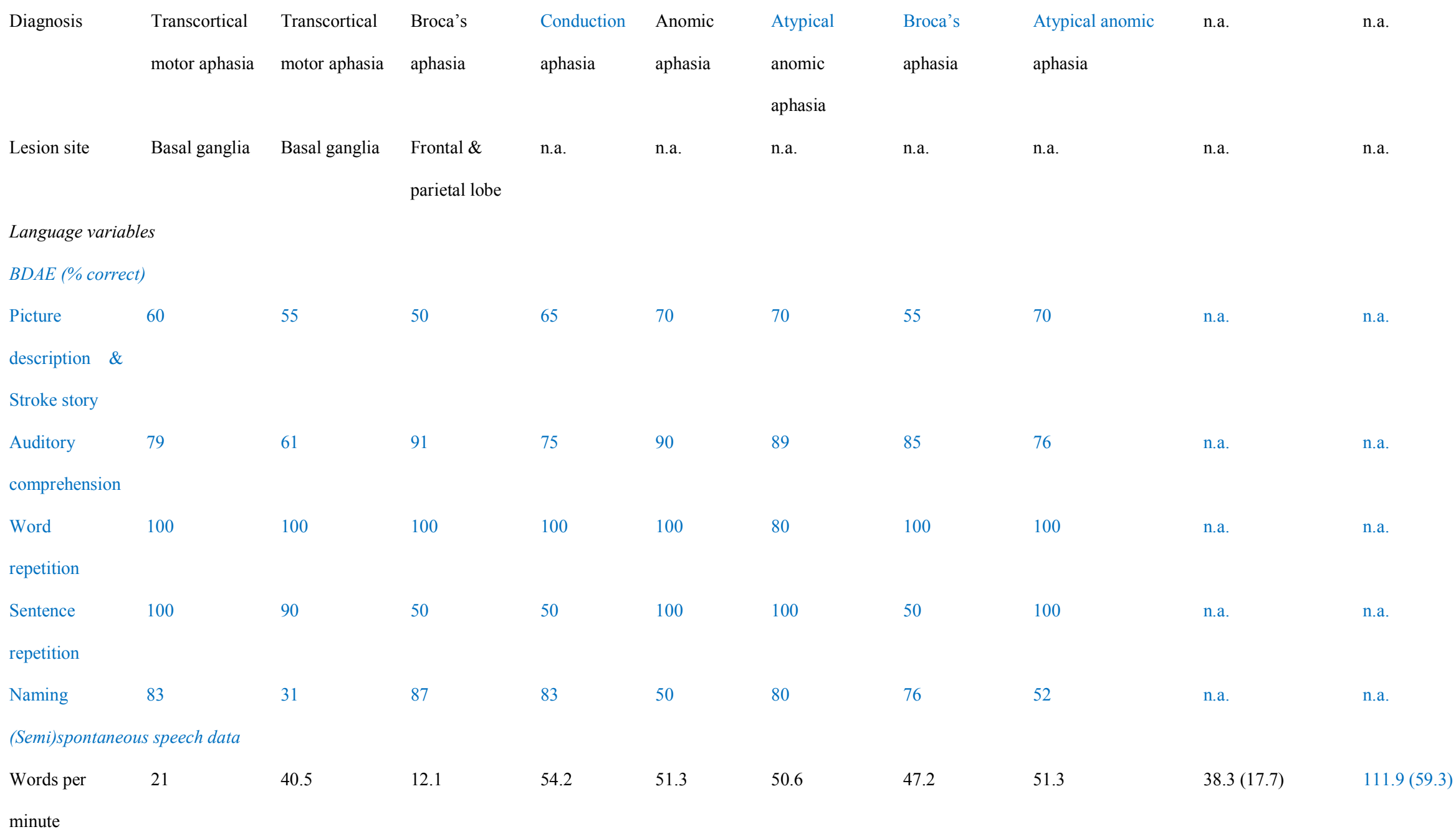


MLU

$\begin{array}{lll}5.2 & 5.9 & 3.7\end{array}$

$\%$ Grammatical

64

sentences

Note 1: The (semi)spontaneous speech data of the control participants were drawn from an unpublished database of neurologically intact Greekspeaking individuals' (semi)spontaneous speech (Fyndanis, Galiussi, \& Christidou, 2014), which was analyzed following the methods and procedures described in the Methods section. To elicit speech from these healthy participants, the experimenter asked them to describe the Cookie Theft picture and to narrate an important event of their life. The (semi)spontaneous speech data of 13 neurologically healthy native speakers of Greek are reported here (mean age $=72.9, \mathrm{SD}=6.2$; mean number of years of formal education $=7.5, \mathrm{SD}=2.5)$

Note 2: Both P6 and P8 were diagnosed with "atypical anomic aphasia". This is not a widely used term. An alternative label for their diagnosis would be "Unclassifiable aphasia". We preferred the term "atypical anomic aphasia", however, to highlight the fact that these PWA had fluent aphasia. 
Table 2. Examples of source sentence-target sentence pairs in the two (local/nonlocal) dependency versions.

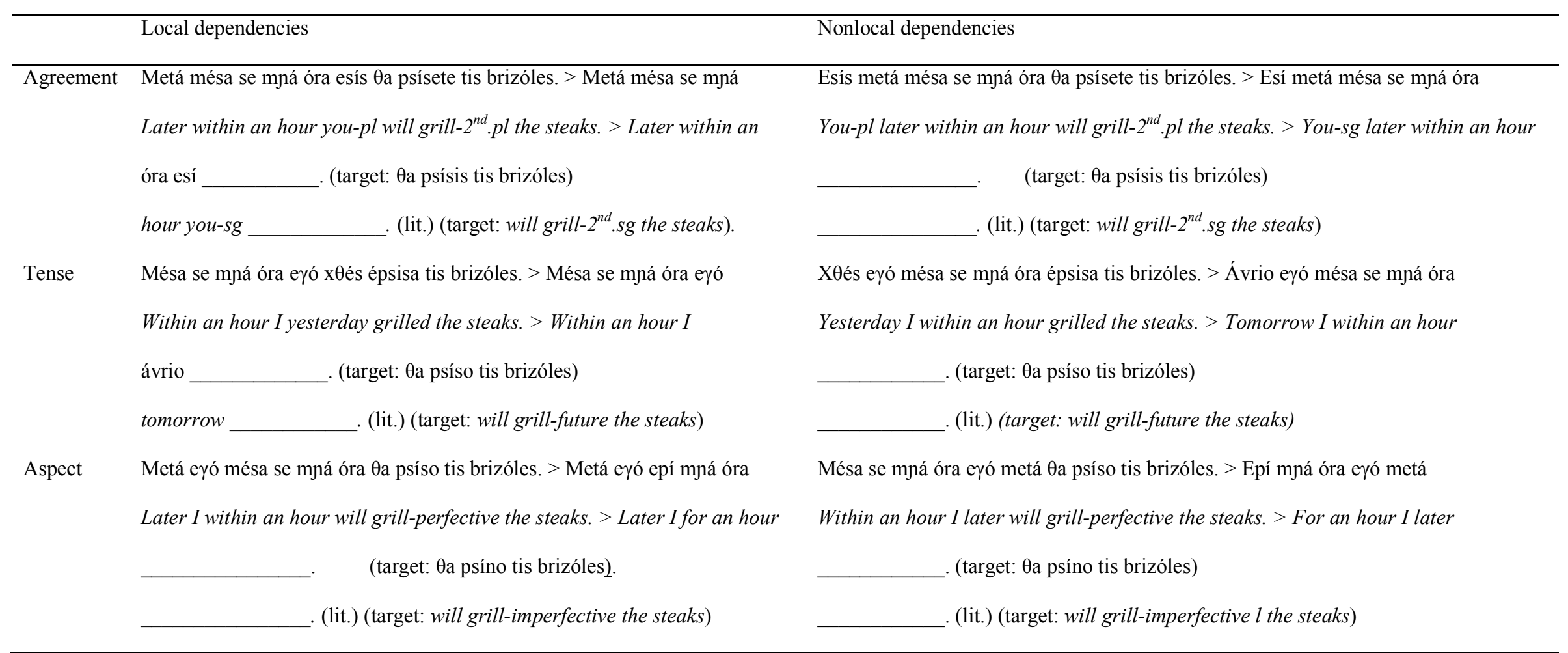


Table 3. Participants' individual and group results (correct).

\begin{tabular}{|c|c|c|c|c|c|c|c|c|c|}
\hline \multirow[t]{2}{*}{ 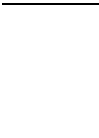 } & \multirow[t]{2}{*}{ WM } & \multicolumn{2}{|l|}{ Agreement } & \multicolumn{2}{|l|}{ Tense } & \multicolumn{2}{|l|}{ Aspect } & \multicolumn{2}{|l|}{ Total } \\
\hline & & $\mathrm{L}$ & NL & $\mathrm{L}$ & NL & $\mathrm{L}$ & NL & $\mathrm{L}$ & NL \\
\hline \multicolumn{10}{|l|}{$P W A$} \\
\hline \multirow[t]{2}{*}{$\mathrm{P} 1$} & $10 / 29$ & $30 / 32$ & $31 / 32$ & $25 / 32$ & $21 / 32$ & $17 / 32$ & $10 / 32$ & $72 / 96$ & $62 / 96$ \\
\hline & & $(94 \%)$ & $(97 \%)$ & $(78 \%)$ & $(66 \%)$ & $(53 \%)$ & $(31 \%)$ & $(75 \%)$ & $(65 \%)$ \\
\hline \multirow[t]{2}{*}{$\mathrm{P} 2$} & $6 / 29$ & $30 / 32$ & $32 / 32$ & $23 / 32$ & $12 / 32$ & $11 / 32$ & $11 / 32$ & $64 / 96$ & $55 / 96$ \\
\hline & & $(94 \%)$ & $(100 \%)$ & $(72 \%)$ & $(38 \%)$ & $(34 \%)$ & $(34 \%)$ & $(67 \%)$ & $(57 \%)$ \\
\hline \multirow[t]{2}{*}{ P3 } & $10 / 29$ & $30 / 32$ & $30 / 32$ & $27 / 32$ & $23 / 32$ & $26 / 32$ & $21 / 32$ & $83 / 96$ & $74 / 96$ \\
\hline & & $(94 \%)$ & $(94 \%)$ & $(84 \%)$ & $(72 \%)$ & $(81 \%)$ & $(66 \%)$ & $(86 \%)$ & $(77 \%)$ \\
\hline \multirow[t]{2}{*}{ P4 } & $8 / 29$ & $28 / 32$ & $30 / 32$ & $16 / 32$ & $28 / 32$ & $4 / 32$ & $8 / 32$ & $48 / 96$ & $66 / 96$ \\
\hline & & $(88 \%)$ & $(94 \%)$ & $(50 \%)$ & $(88 \%)$ & $(13 \%)$ & $(25 \%)$ & $(50 \%)$ & $(69 \%)$ \\
\hline \multirow[t]{2}{*}{ P5 } & $11 / 29$ & $31 / 32$ & $32 / 32$ & $31 / 32$ & $29 / 32$ & $12 / 32$ & $11 / 32$ & $74 / 96$ & $72 / 96$ \\
\hline & & $(97 \%)$ & $(100 \%)$ & $(97 \%)$ & $(91 \%)$ & $(38 \%)$ & $(34 \%)$ & $(77 \%)$ & $(75 \%)$ \\
\hline \multirow[t]{2}{*}{ P6 } & $7 / 29$ & $29 / 32$ & $30 / 32$ & $24 / 32$ & $26 / 32$ & $10 / 32$ & $15 / 32$ & $63 / 96$ & $71 / 96$ \\
\hline & & $(91 \%)$ & $(94 \%)$ & $(75 \%)$ & $(81 \%)$ & $(31 \%)$ & $(47 \%)$ & $(66 \%)$ & $(74 \%)$ \\
\hline \multirow[t]{2}{*}{ P7 } & $9 / 29$ & $27 / 32$ & $27 / 32$ & $19 / 32$ & $15 / 32$ & $11 / 32$ & $11 / 32$ & $57 / 96$ & $53 / 96$ \\
\hline & & $(84 \%)$ & $(84 \%)$ & $(59 \%)$ & $(47 \%)$ & $(34 \%)$ & $(34 \%)$ & $(59 \%)$ & $(55 \%)$ \\
\hline \multirow[t]{2}{*}{ P8 } & $4 / 29$ & $31 / 32$ & $28 / 32$ & $5 / 32$ & $15 / 32$ & $13 / 32$ & $11 / 32$ & $49 / 96$ & $54 / 96$ \\
\hline & & $(97 \%)$ & $(88 \%)$ & $(16 \%)$ & $(47 \%)$ & $(41 \%)$ & $(34 \%)$ & $(51 \%)$ & $(56 \%)$ \\
\hline \multirow[t]{2}{*}{ Total } & $8.1(2.4) / 29$ & $236 / 256$ & $240 / 256$ & $170 / 256$ & $169 / 256$ & $104 / 256$ & $98 / 256$ & $510 / 768$ & $507 / 768$ \\
\hline & & $(92 \%)$ & $(94 \%)$ & $(66 \%)$ & $(66 \%)$ & $(41 \%)$ & $(38 \%)$ & $(66 \%)$ & $(66 \%)$ \\
\hline \multicolumn{10}{|c|}{ Controls } \\
\hline \multirow[t]{2}{*}{$\mathrm{C} 1$} & $15 / 29$ & $32 / 32$ & $32 / 32$ & $32 / 32$ & $26 / 32$ & $28 / 32$ & $28 / 32$ & $92 / 96$ & $86 / 96$ \\
\hline & & $(100 \%)$ & $(100 \%)$ & $(100 \%)$ & $(81 \%)$ & $(88 \%)$ & $(88 \%)$ & $(96 \%)$ & $(90 \%)$ \\
\hline \multirow[t]{2}{*}{$\mathrm{C} 2$} & $22 / 29$ & $32 / 32$ & $32 / 32$ & $32 / 32$ & $32 / 32$ & $31 / 32$ & $26 / 32$ & $95 / 96$ & $90 / 96$ \\
\hline & & $(100 \%)$ & $(100 \%)$ & $(100 \%)$ & $(100 \%)$ & $(97 \%)$ & $(81 \%)$ & $(99 \%)$ & $(94 \%)$ \\
\hline \multirow[t]{2}{*}{$\mathrm{C} 3$} & $18 / 29$ & $32 / 32$ & $32 / 32$ & $32 / 32$ & $32 / 32$ & $31 / 32$ & $31 / 32$ & $95 / 96$ & $95 / 96$ \\
\hline & & $(100 \%)$ & $(100 \%)$ & $(100 \%)$ & $(100 \%)$ & $(97 \%)$ & $(97 \%)$ & $(99 \%)$ & $(99 \%)$ \\
\hline
\end{tabular}




\begin{tabular}{|c|c|c|c|c|c|c|c|c|c|}
\hline $\mathrm{C} 4$ & $18 / 29$ & $\begin{array}{l}32 / 32 \\
(100 \%)\end{array}$ & $\begin{array}{l}32 / 32 \\
(100 \%)\end{array}$ & $\begin{array}{l}32 / 32 \\
(100 \%)\end{array}$ & $\begin{array}{l}32 / 32 \\
(100 \%)\end{array}$ & $\begin{array}{l}32 / 32 \\
(100 \%)\end{array}$ & $\begin{array}{l}31 / 32 \\
(97 \%)\end{array}$ & $\begin{array}{l}96 / 96 \\
(100 \%)\end{array}$ & $\begin{array}{l}95 / 96 \\
(99 \%)\end{array}$ \\
\hline $\mathrm{C} 5$ & $12 / 29$ & $\begin{array}{l}32 / 32 \\
(100 \%)\end{array}$ & $\begin{array}{l}31 / 32 \\
(97 \%)\end{array}$ & $\begin{array}{l}32 / 32 \\
(100 \%)\end{array}$ & $\begin{array}{l}32 / 32 \\
(100 \%)\end{array}$ & $\begin{array}{l}27 / 32 \\
(84 \%)\end{array}$ & $\begin{array}{l}13 / 32 \\
(41 \%)\end{array}$ & $\begin{array}{l}91 / 96 \\
(95 \%)\end{array}$ & $\begin{array}{l}76 / 96 \\
(79 \%)\end{array}$ \\
\hline C6 & $17 / 29$ & $\begin{array}{l}32 / 32 \\
(100 \%)\end{array}$ & $\begin{array}{l}32 / 32 \\
(100 \%)\end{array}$ & $\begin{array}{l}32 / 32 \\
(100 \%)\end{array}$ & $\begin{array}{l}31 / 32 \\
(97 \%)\end{array}$ & $\begin{array}{l}17 / 32 \\
(53 \%)\end{array}$ & $\begin{array}{l}17 / 32 \\
(53 \%)\end{array}$ & $\begin{array}{l}81 / 96 \\
(84 \%)\end{array}$ & $\begin{array}{l}80 / 96 \\
(83 \%)\end{array}$ \\
\hline $\mathrm{C} 7$ & $12 / 29$ & $\begin{array}{l}29 / 32 \\
(91 \%)\end{array}$ & $\begin{array}{l}29 / 32 \\
(91 \%)\end{array}$ & $\begin{array}{l}22 / 32 \\
(69 \%)\end{array}$ & $\begin{array}{l}21 / 32 \\
(66 \%)\end{array}$ & $\begin{array}{l}9 / 32 \\
(28 \%)\end{array}$ & $\begin{array}{l}7 / 32 \\
(22 \%)\end{array}$ & $\begin{array}{l}60 / 96 \\
(63 \%)\end{array}$ & $\begin{array}{l}58 / 96 \\
(60 \%)\end{array}$ \\
\hline $\mathrm{C} 8$ & $8 / 29$ & $\begin{array}{l}30 / 32 \\
(94 \%)\end{array}$ & $\begin{array}{l}32 / 32 \\
(100 \%)\end{array}$ & $\begin{array}{l}32 / 32 \\
(100 \%)\end{array}$ & $\begin{array}{l}26 / 32 \\
(81 \%)\end{array}$ & $\begin{array}{l}20 / 32 \\
(63 \%)\end{array}$ & $\begin{array}{l}9 / 32 \\
(28 \%)\end{array}$ & $\begin{array}{l}82 / 96 \\
(85 \%)\end{array}$ & $\begin{array}{l}67 / 96 \\
(70 \%)\end{array}$ \\
\hline otal & $15.3(4.4) / 29$ & $\begin{array}{l}251 / 256 \\
(98 \%)\end{array}$ & $\begin{array}{l}252 / 256 \\
(98 \%)\end{array}$ & $\begin{array}{l}246 / 256 \\
(96 \%)\end{array}$ & $\begin{array}{l}232 / 256 \\
(90 \%)\end{array}$ & $\begin{array}{l}195 / 256 \\
(76 \%)\end{array}$ & $\begin{array}{l}163 / 256 \\
(64 \%)\end{array}$ & $\begin{array}{l}692 / 768 \\
(90 \%)\end{array}$ & $\begin{array}{l}647 / 768 \\
(84 \%)\end{array}$ \\
\hline
\end{tabular}


Table 4. Linear mixed-effect model on Accuracy fitted to Dataset 1 (8 aphasic and 8 control participants) (Model 1). The model included the additive effect of Morphosyntactic Condition and WM, and the interaction between the two. The model also included a random intercept for Subjects $(\mathrm{SD}=0.068)$.

\begin{tabular}{llllll}
\hline Term & Estimate & Standard & $\mathbf{d f}$ & $\mathbf{t}$ value & $\operatorname{Pr}(>|\mathbf{t}|)$ \\
& \multicolumn{7}{c}{ Error } & & \\
\hline (Intercept; Condition = Agreement) & 0.9 & 0.084 & 32 & 11 & $<0.001^{*}$ \\
Condition=Aspect & -0.87 & 0.093 & 66 & -9.3 & $<0.001^{*}$ \\
Condition=Tense & -0.34 & 0.093 & 66 & -3.6 & $<0.001^{*}$ \\
WM & 0.005 & 0.006 & 32 & 0.79 & 0.44 \\
Condition=Aspect : WM & 0.038 & 0.007 & 66 & 5.4 & $<0.001^{*}$ \\
Condition=Tense : WM & 0.018 & 0.007 & 66 & 2.6 & $0.012^{*}$ \\
\hline Intercept; Condition = Aspect) & 0.039 & 0.084 & 32 & 0.47 & 0.64 \\
Condition=Agreement & 0.866 & 0.093 & 66 & 9.3 & $<0.001^{*}$ \\
Condition=Tense & 0.526 & 0.093 & 66 & 5.65 & $<0.001^{*}$ \\
WM & 0.043 & 0.006 & 32 & 6.82 & $<0.001^{*}$ \\
Condition=Agreement : WM & -0.038 & 0.007 & 66 & -5.43 & $<0.001^{*}$ \\
Condition=Tense : WM & -0.020 & 0.007 & 66 & -2.85 & $<0.01^{*}$ \\
\hline
\end{tabular}

The symbol * indicates significant effects. 
Table 5. Linear mixed-effect model on Accuracy fitted to Dataset 2 (103 healthy participants) (Model 2). The model included the additive effect of Morphosyntactic Condition, Locality, WM and Age, and the interaction between Morphosyntactic Condition, Locality and WM. The model also included a random intercept for Subjects $(\mathrm{SD}=0.084)$.

\begin{tabular}{llllll}
\hline Term & Estimate & Standard & df & t value & $\operatorname{Pr}(>|\mathbf{t}|)$ \\
& \multicolumn{7}{c}{ Error } \\
\hline (Intercept; Condition = Agreement) & 1.1 & 0.063 & 120 & 18 & $<0.001^{*}$ \\
Condition=Aspect & 0.64 & 0.032 & 510 & -20 & $<0.001^{*}$ \\
Condition=Tense & -0.29 & 0.032 & 510 & -9.2 & $<0.001^{*}$ \\
WM & -0.002 & 0.002 & 150 & -0.6 & 0.55 \\
Age & -0.002 & 0.001 & 100 & -3.1 & $0.002^{*}$ \\
Condition=Aspect : WM & 0.029 & 0.002 & 511 & 17 & $<0.001^{*}$ \\
Condition=Tense : WM & 0.015 & 0.002 & 511 & 8.3 & $<0.001^{*}$ \\
\hline Intercept; Condition = Aspect) & 0.47 & 0.063 & 120 & 7.5 & $<0.001^{*}$ \\
Condition=Agreement & 0.64 & 0.032 & 510 & 20 & $<0.001^{*}$ \\
Condition=Tense & 0.34 & 0.032 & 510 & 11 & $<0.001^{*}$ \\
WM & 0.028 & 0.002 & 150 & 12 & $<0.001^{*}$ \\
Age & -0.002 & 0.001 & 100 & -3.1 & $0.002^{*}$ \\
Condition=Agreement : WM & -0.029 & 0.002 & 511 & -17 & $<0.001^{*}$ \\
Condition=Tense : WM & -0.015 & 0.002 & 511 & -8.3 & $<0.001^{*}$ \\
\hline The symbol * indicas & & & & &
\end{tabular}

The symbol * indicates significant effects. 
Figure 1. Distribution of participants across lifespan decades. The $x$-axis represents the age range taken into account, separated in bins. The height of the columns in the $y$-axis is proportional to the number of observations for the age bin.

$77 \times 77 \mathrm{~mm}(600 \times 600 \mathrm{DPI})$

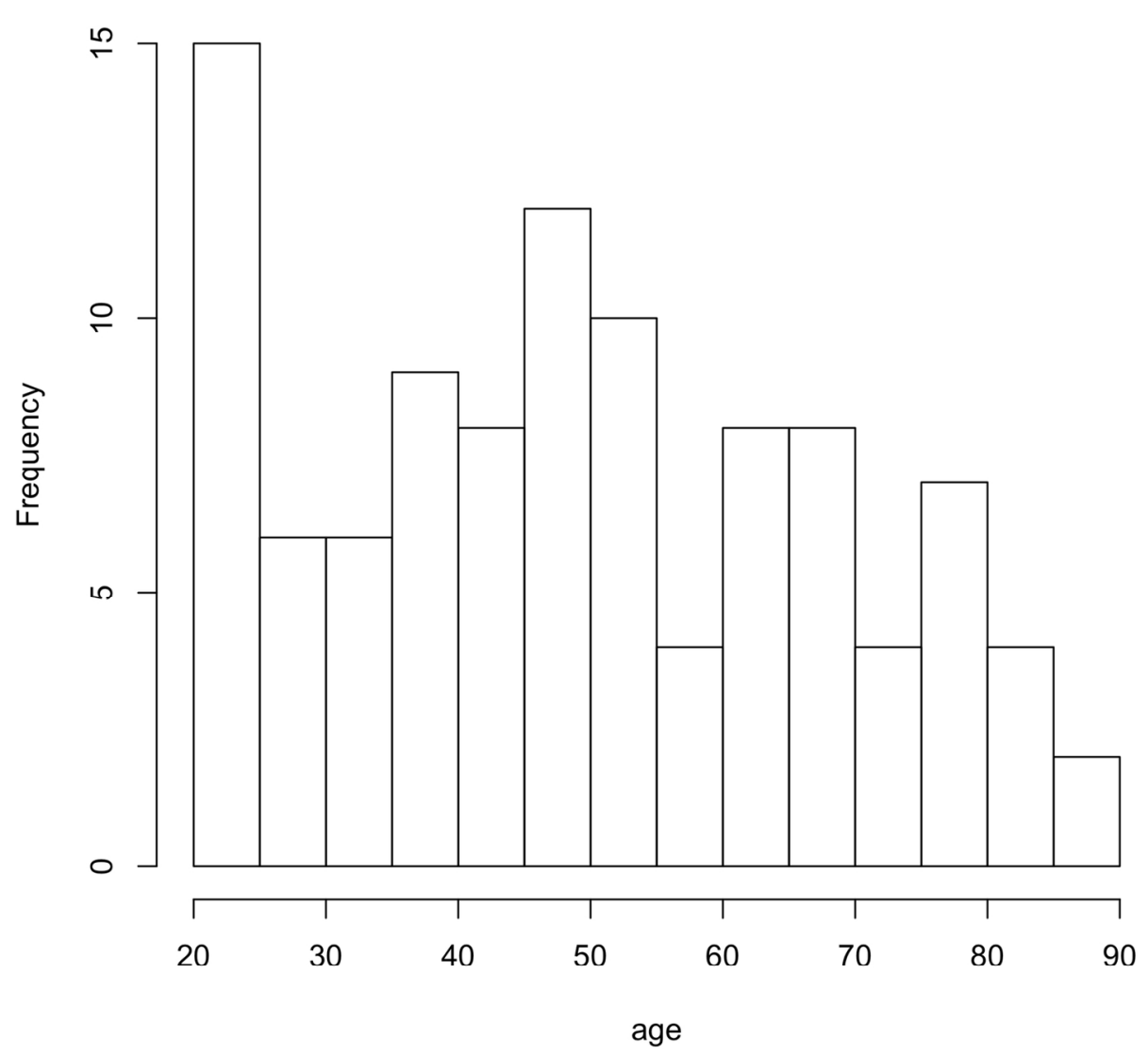


Figure 2. The plot depicts the significant interaction between Morphosyntactic Condition and WM of Model 1 fitted to Dataset 1 ( 8 aphasic and 8 control participants). The plot shows that the more limited the verbal WM capacity, the larger the difference between the three morphosyntactic categories. WM did not affect subject-verb agreement, but did affect aspect and -to a lesser extent- tense. !! + 
Figure 3. The plot depicts the significant interaction between Morphosyntactic Condition and WM of Model 2 fitted to Dataset 2 (103 healthy participants). The plot shows that the more limited the verbal WM capacity, the larger the difference between the three morphosyntactic categories. WM did not affect subject-verb agreement, but did affect aspect and -to a lesser extent- tense. !! †

$$
1058 \times 423 \mathrm{~mm}(72 \times 72 \mathrm{DPI})
$$




\section{ARTICULATORY AGILITY \\ facility at phoneme and syllable level \\ PHRASE LENGTH \\ longest occasional uninterrupted word runs}

GRAMMATICAL FORM

variety of grammatical constructions; use of grammatical morphemes

MELODIC LINE (PROSODY)

PARAPHASIA IN RUNNING SPEECH

(Rate only if PHRASE LENGTH is 4 or more)

WORD FINDING RELATIVE TO FLUENCY

\section{SENTENCE REPETITION}

Percentile Score

AUDITORY COMPREHENSION

Mean percentile of the 3 standard subtests

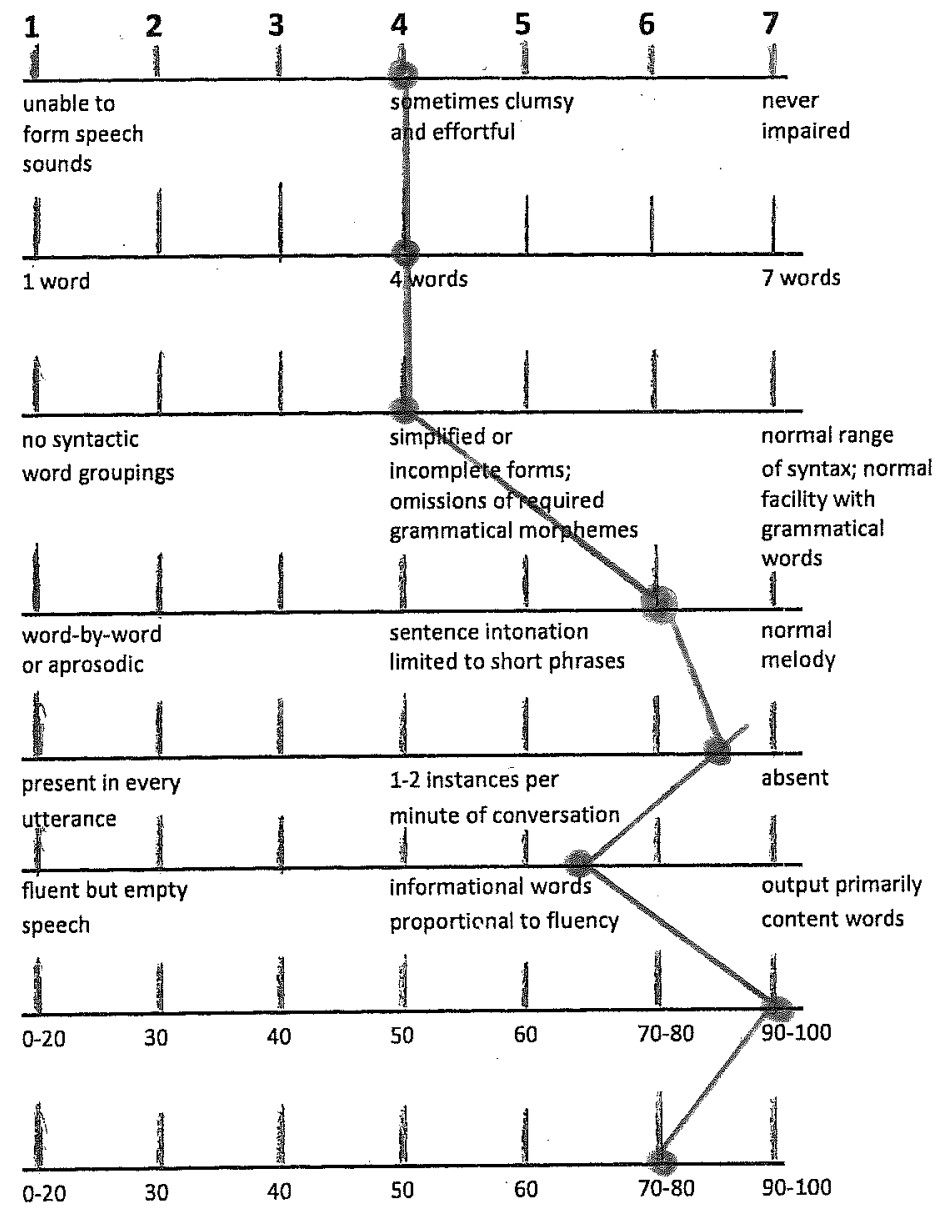


RATING SCALE PROFILE OF SPEECH CHARACTERISTICS

\section{ARTICULATORY AGILITY}

facility at phoneme and syllable level

\section{PHRASE LENGTH}

longest occasional uninterrupted word runs

\section{GRAMMATICAL FORM}

variety of grammatical constructions; use of grammatical morphemes

MELODIC LINE (PROSODY)

PARAPHASIA IN RUNNING SPEECH

(Rate only if PHRASE LENGTH is 4 or more)

WORD FINDING RELATIVE TO FLUENCY

\section{SENTENCE REPETITION}

Percentile Score

\section{AUDITORY COMPREHENSION}

Mean percentile of the 3 standard subtests
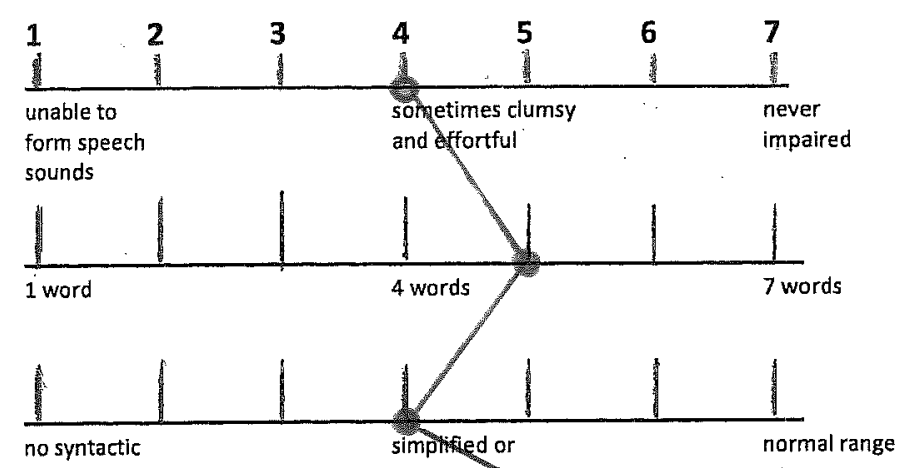

word groupings incompletefarms; of syntax; normal
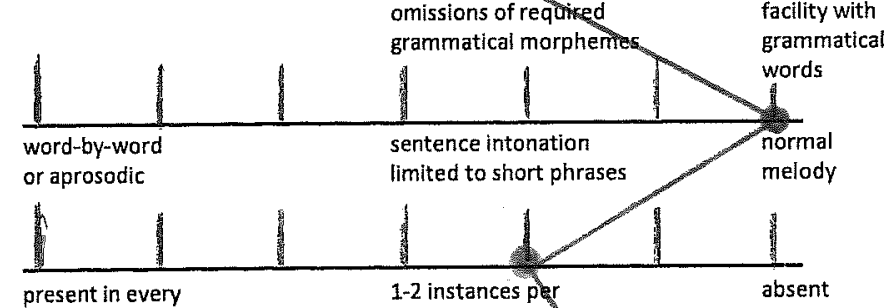

present in every 1-2 instances per absent
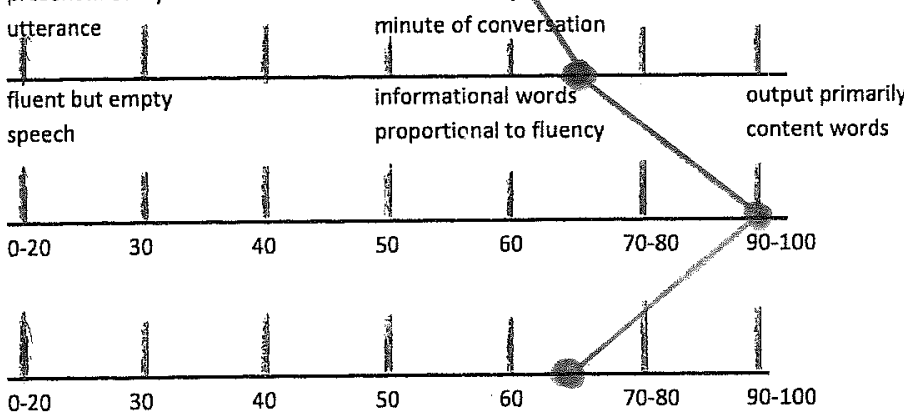
RATING SCALE PROFILE OF SPEECH CHARACTERISTICS

\section{ARTICULATORY AGILITY}

facility at phoneme and syllable level

\section{PHRASE LENGTH}

longest occasional uninterrupted word runs

\section{GRAMMATICAL FORM}

variety of grammatical constructions; use of grammatical morphemes

\section{MELODIC LINE (PROSODY)}

PARAPHASIA IN RUNNING SPEECH

(Rate only if PHRASE LENGTH is 4 or more)

WORD FINDING RELATIVE TO FLUENCY

\section{SENTENCE REPETITION}

Percentile Score

\section{AUDITORY COMPREHENSION}

Mean percentile of the 3 standard subtests

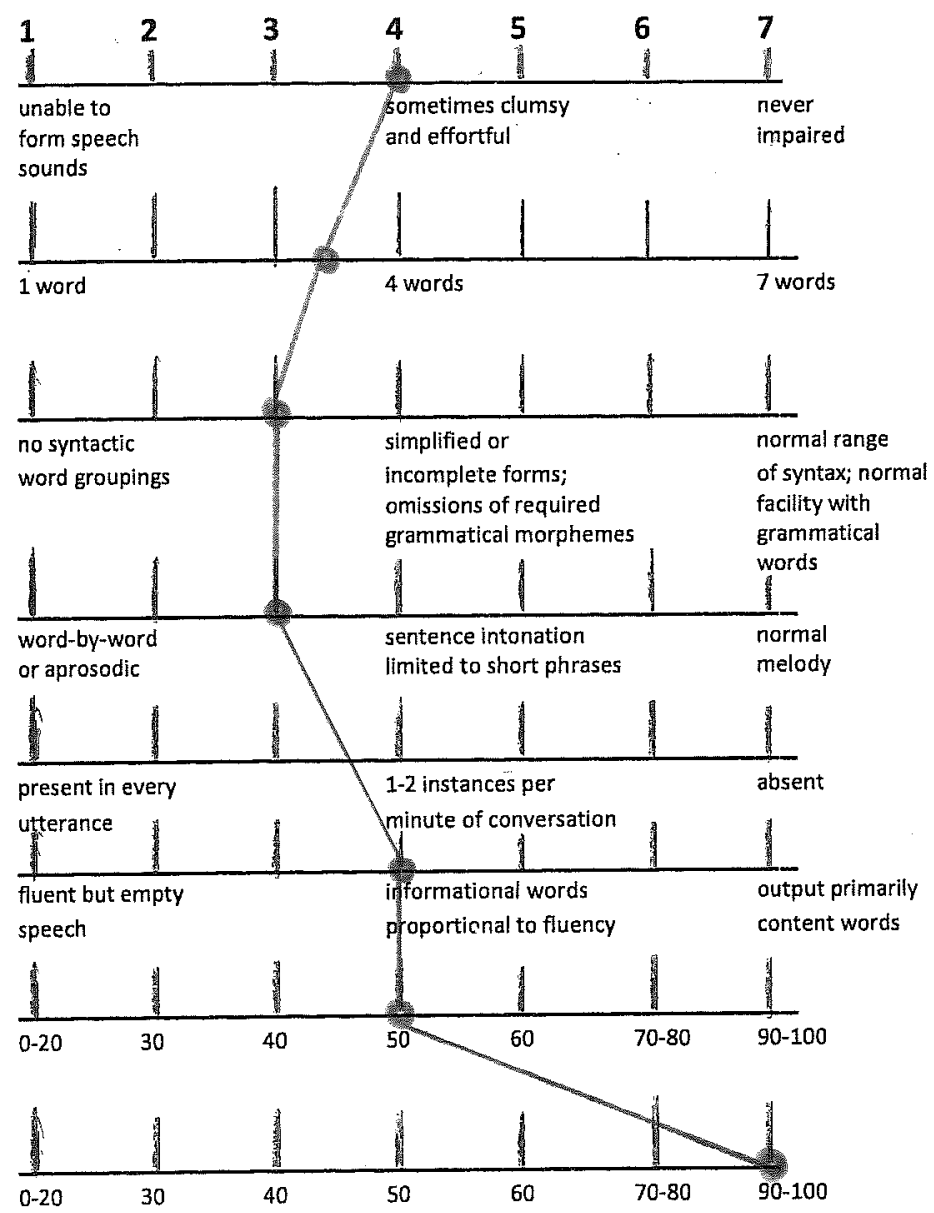




\section{RATING SCALE PROFILE OF SPEECH CHARACTERISTICS P}

\section{ARTICULATORY AGILITY \\ facility at phoneme and syllable level}

\section{PHRASE LENGTH}

longest occasional uninterrupted word runs

\section{GRAMMATICAL FORM}

variety of grammatical constructions; use of grammatical morphemes

MELODIC LINE (PROSODY)

\section{PARAPHASIA IN RUNNING SPEECH}

(Rate only if PHRASE LENGTH is 4 or mare)

WORD FINDING RELATIVE TO FLUENCY

SENTENCE REPETITION

Percentile Score

\section{AUDITORY COMPREHENSION}

Mean percentile of the 3 standard subtests
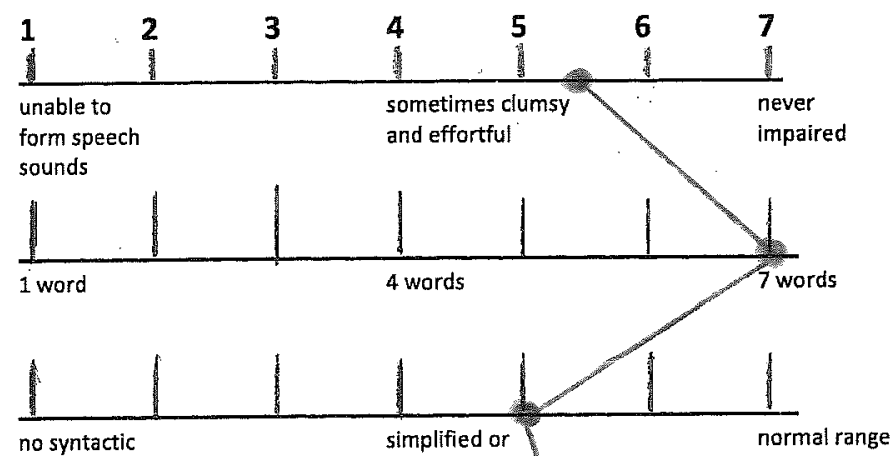

$\begin{array}{lll}\text { no syntactic } & \text { simplified or } & \text { normal range } \\ \text { word groupings } & \text { incomplete forms; } & \text { of syntax; normal }\end{array}$ omissions of required facility with
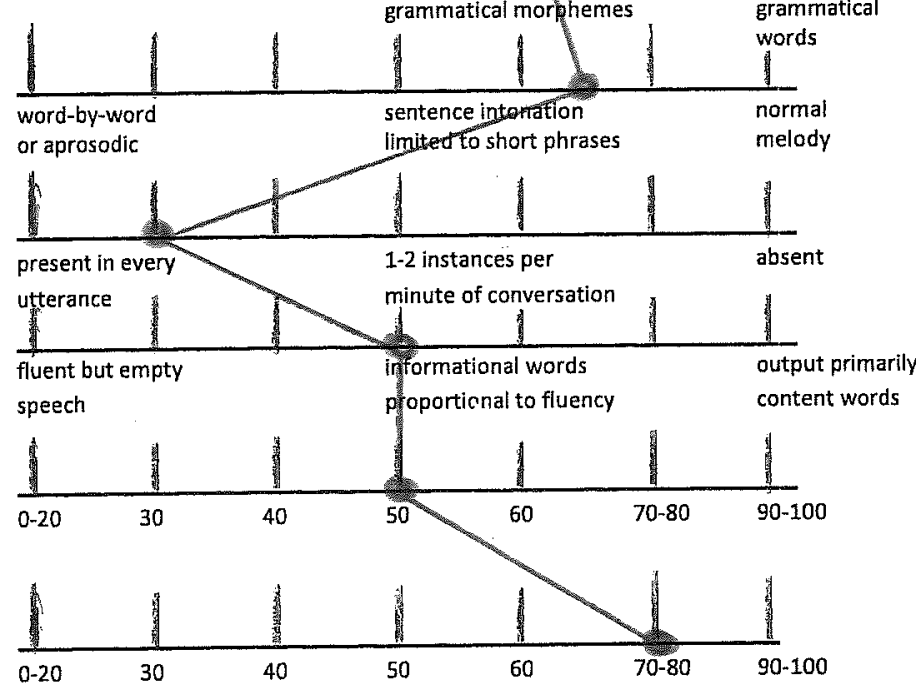


\section{ARTICULATORY AGILITY}

facility at phoneme and syllable level

\section{PHRASE LENGTH}

longest occasional uninterrupted word runs

\section{GRAMMATICAL. FORM}

variety of grammatical constructions; use of grammatical morphemes

MELODIC LINE (PROSODY)

\section{PARAPHASIA IN RUNNING SPEECH}

(Rate only if PHRASE LENGTH is 4 or more)

\section{WORD FINDING RELATIVE TO FLUENCY}

\section{SENTENCE REPETITION}

Percentile Score

\section{AUDITORY COMPREHENSION}

Mean percentile of the 3 standard subtests
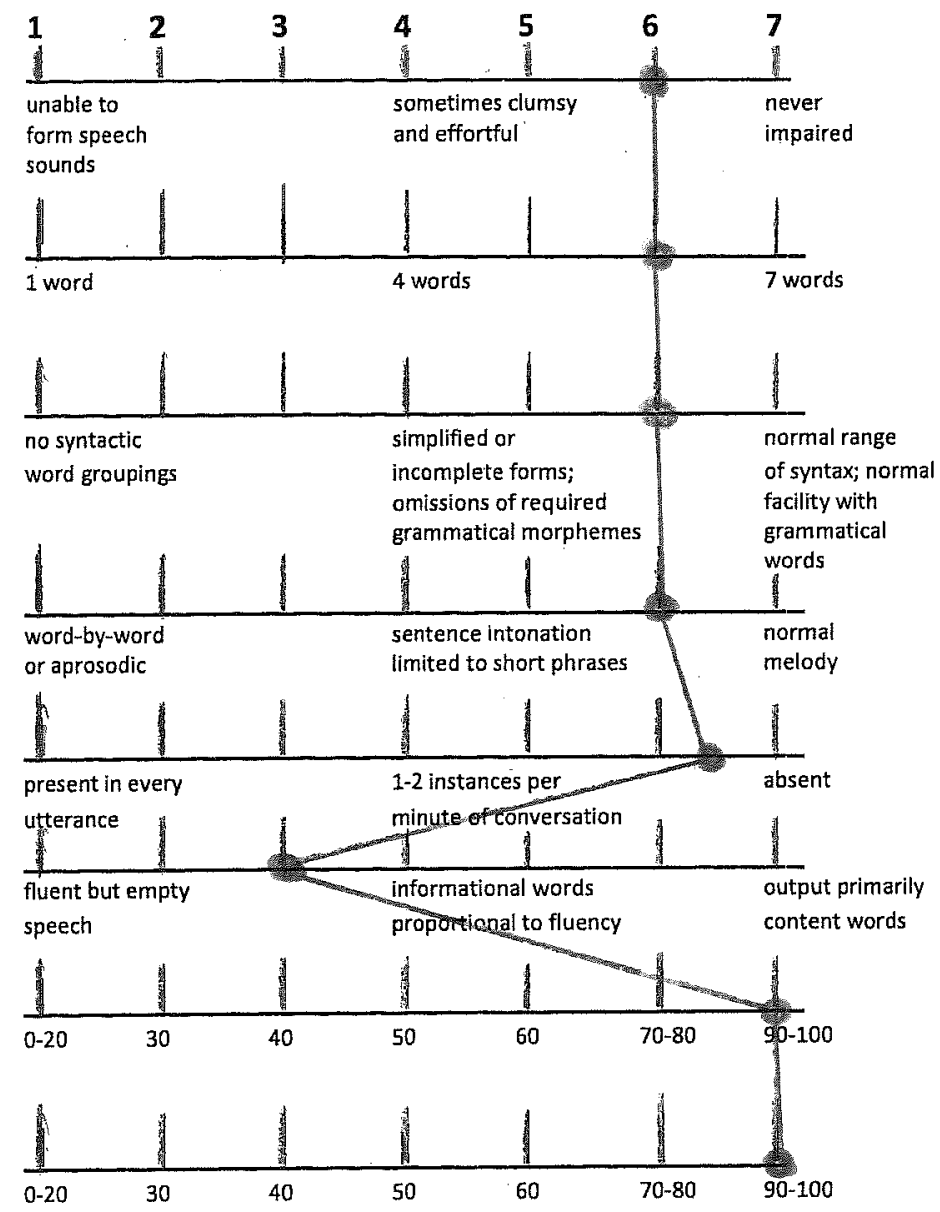


\section{RATING SCALE PROFILE OF SPEECH CHARACTERISTICS}

\section{ARTICULATORY AGILITY}

facility at phoneme and syllable level

\section{PHRASE LENGTH}

longest occasional uninterrupted word runs

\section{GRAMMATICAL FORM}

variety of grammatical constructions; use of grammatical morphemes

MELODIC LINE (PROSODY)

PARAPHASIA IN RUNNING SPEECH

(Rate only if PHRASE LENGTH is 4 or more)

WORD FINDING RELATIVE TO FLUENCY

\section{SENTENCE REPETITION}

Percentile Score

\section{AUDITORY COMPREHENSION}

Mean percentile of the 3 standard subtests
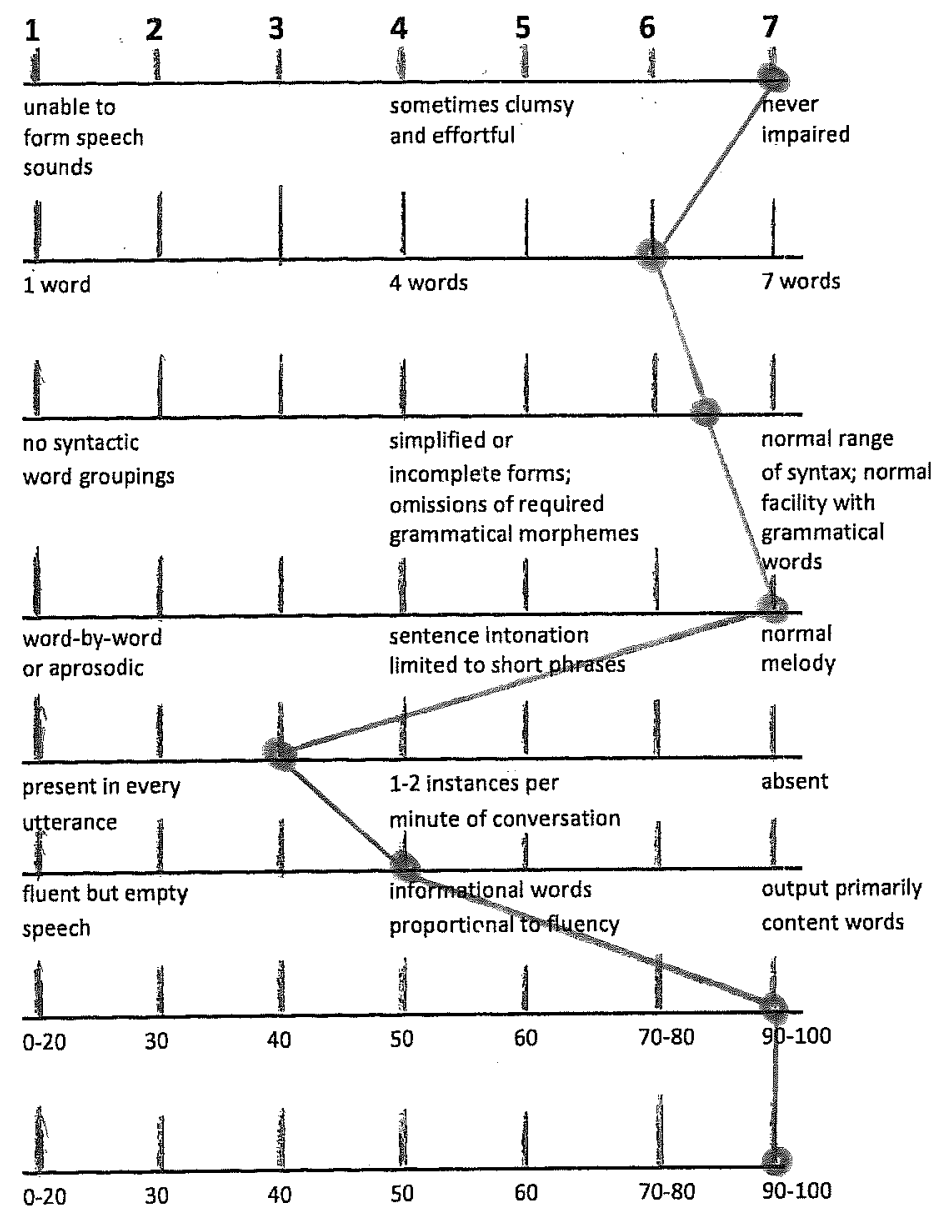


\section{ARTICULATORY AGILITY}

facility at phoneme and syllable level

\section{PHRASE LENGTH}

longest occasional uninterrupted word runs

\section{GRAMMATICAL FORM}

variety of grammatical constructions;

use of grammatical morphemes

MELODIC LINE (PROSODY)

\section{PARAPHASIA IN RUNNING SPEECH}

(Rate only if PHRASE LENGTH is 4 or more)

WORD FINDING RELATIVE TO FLUENCY

\section{SENTENCE REPETITION}

Percentile Score

\section{AUDITORY COMPREHENSION}

Mean percentile of the 3 standard subtests
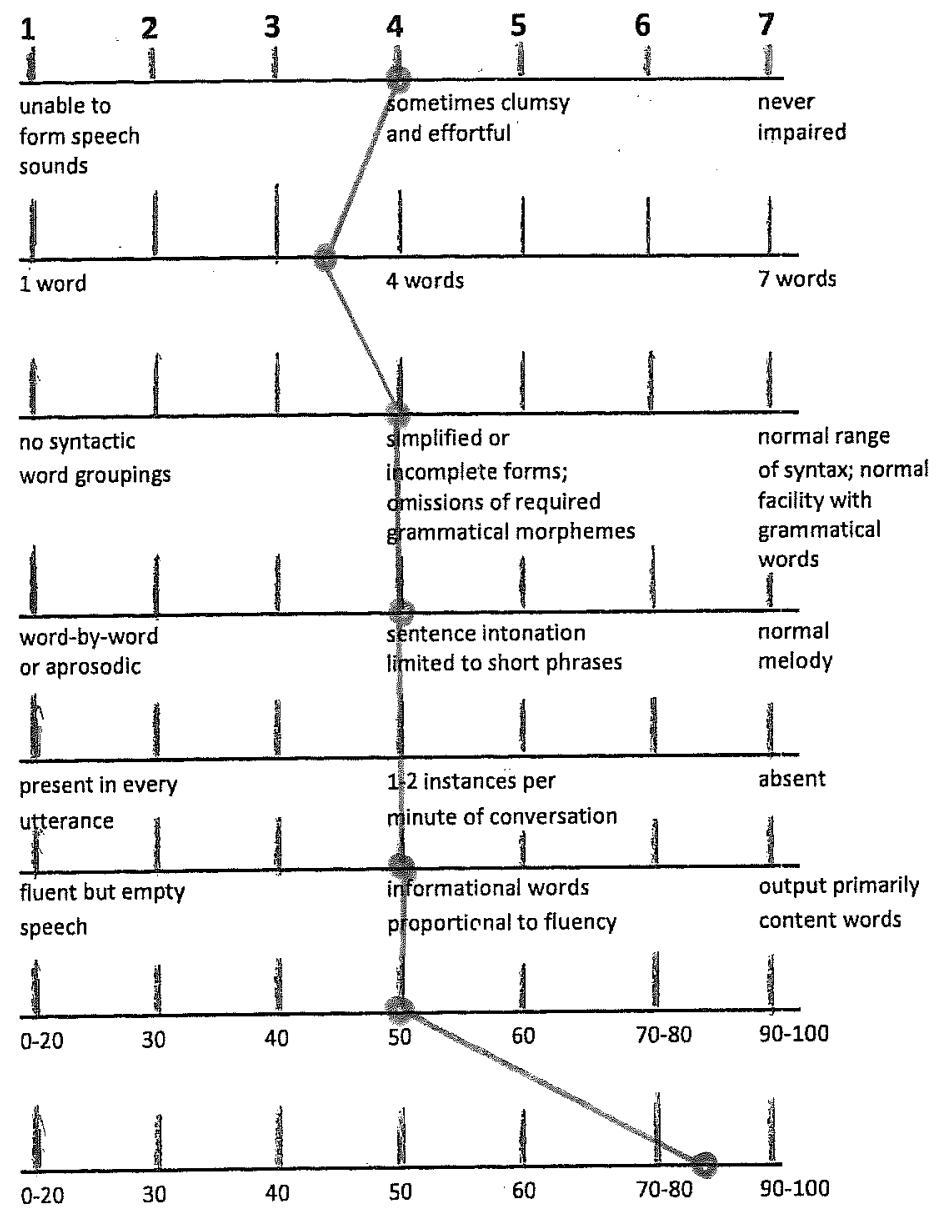


\title{
RATING SCALE PROFILE OF SPEECH CHARACTERISTICS P 8
}

\author{
ARTICULATORY AGILITY \\ facility at phoneme and syllable level \\ PHRASE LENGTH \\ longest occasional uninterrupted word runs \\ GRAMMATICAL FORM \\ variety of grammatical constructions; \\ use of grammatical morphemes \\ MELODIC LINE (PROSODY) \\ PARAPHASIA IN RUNNING SPEECH \\ (Rate only if PHRASE LENGTH is 4 or more) \\ WORD FINDING RELATIVE TO FLUENCY \\ SENTENCE REPETITION \\ Percentile Score \\ AUDITORY COMPREHENSION \\ Mean percentile of the 3 standard subtests
}
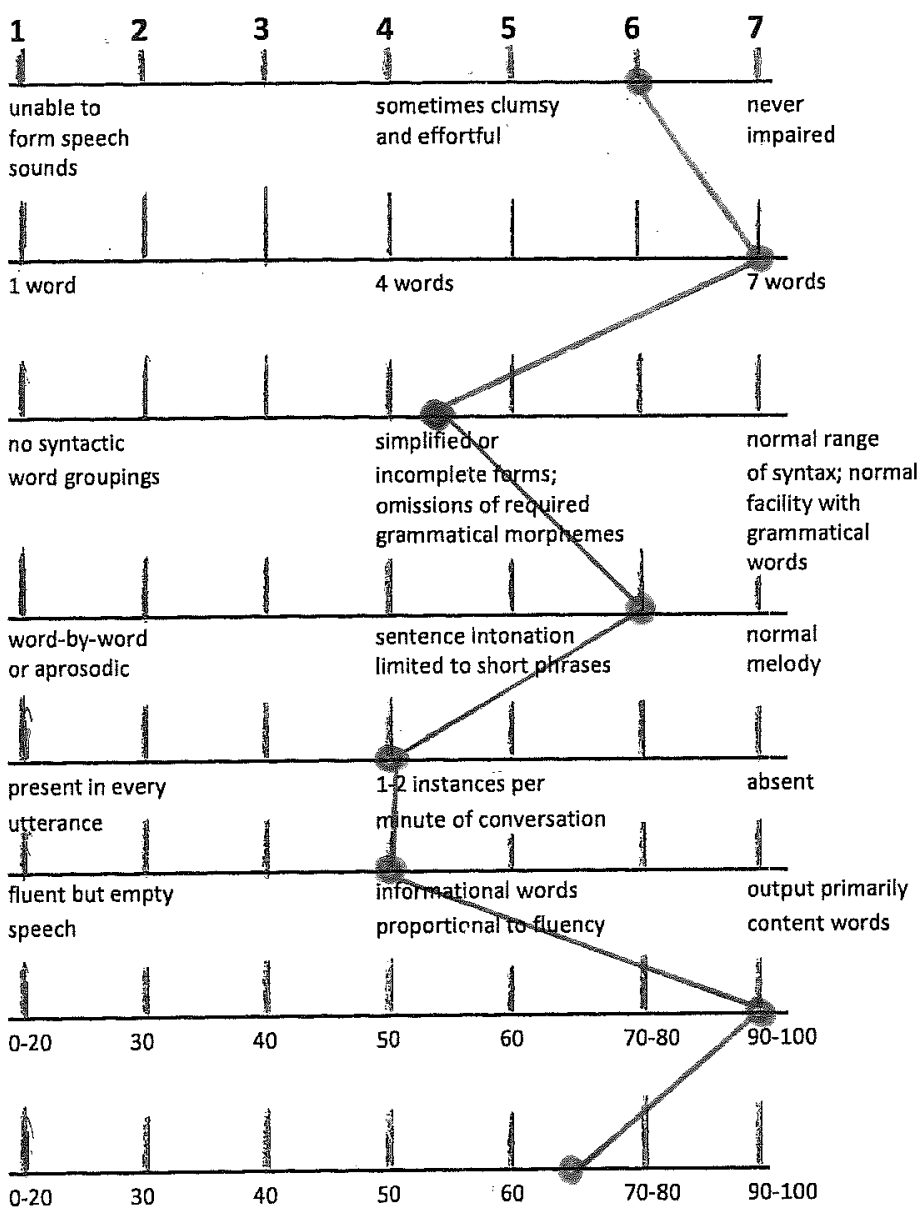

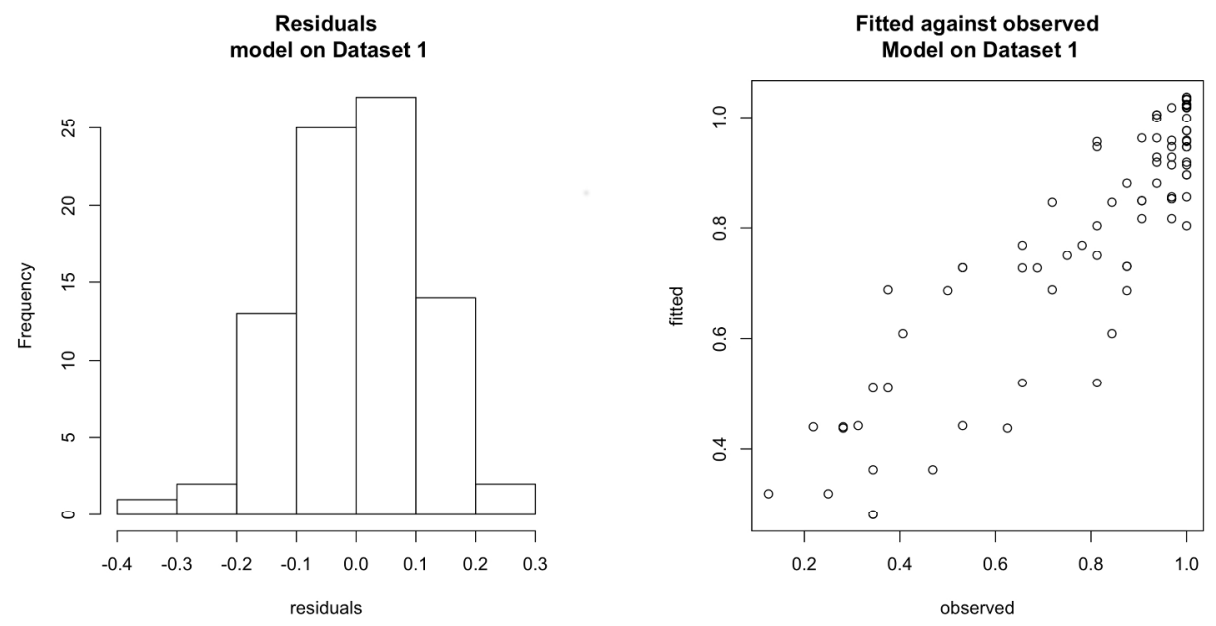

Supplementary Materials 2. Diagnostics for Model 1.

$846 \times 423 \mathrm{~mm}(72 \times 72$ DPI $)$ 
Dataset 1

\section{WM Capacity partial residuals}

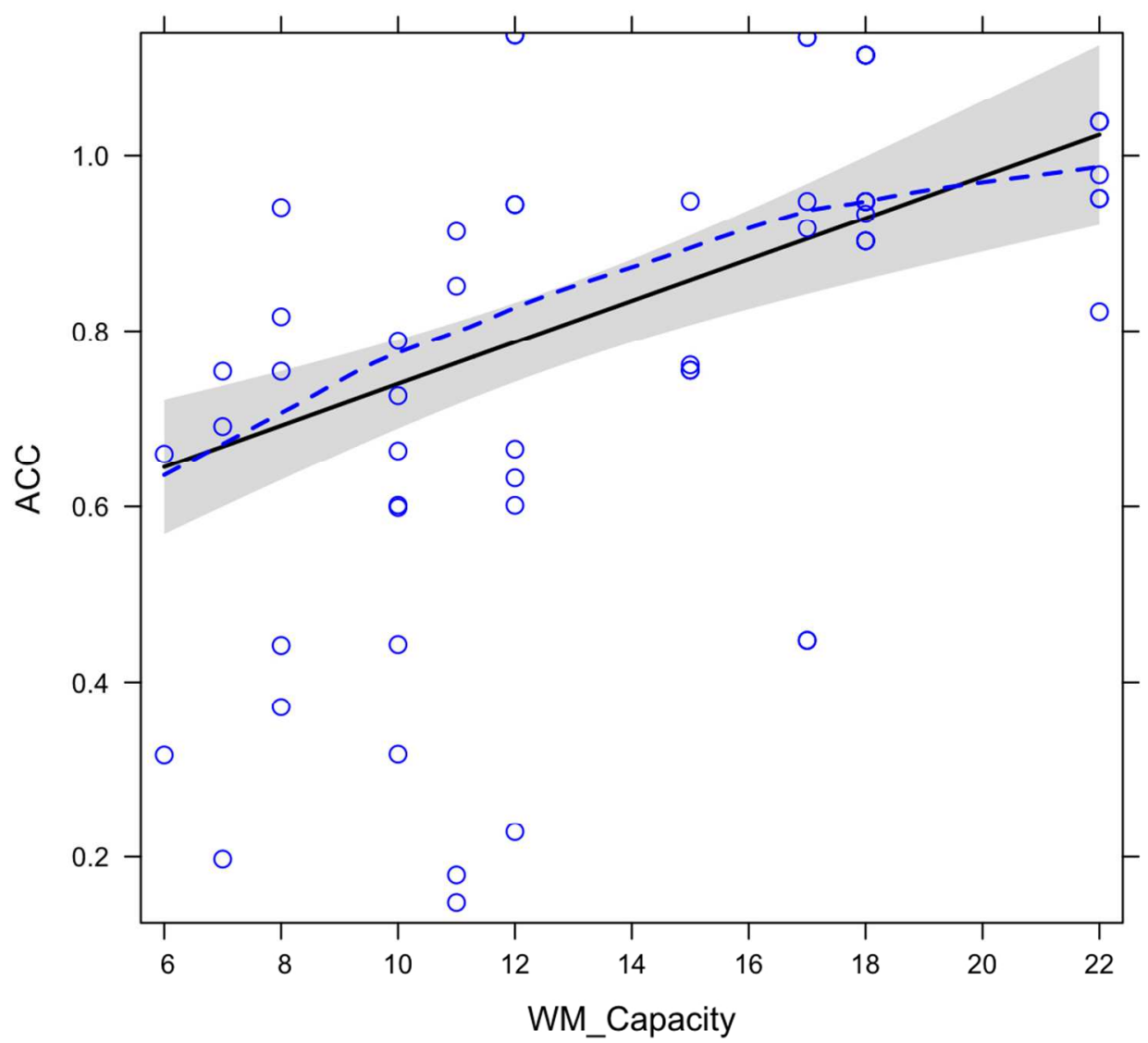

Supplementary Materials 3. Partial residuals for WM in Model 1.

$423 \times 423 \mathrm{~mm}(72 \times 72 \mathrm{DPI})$ 

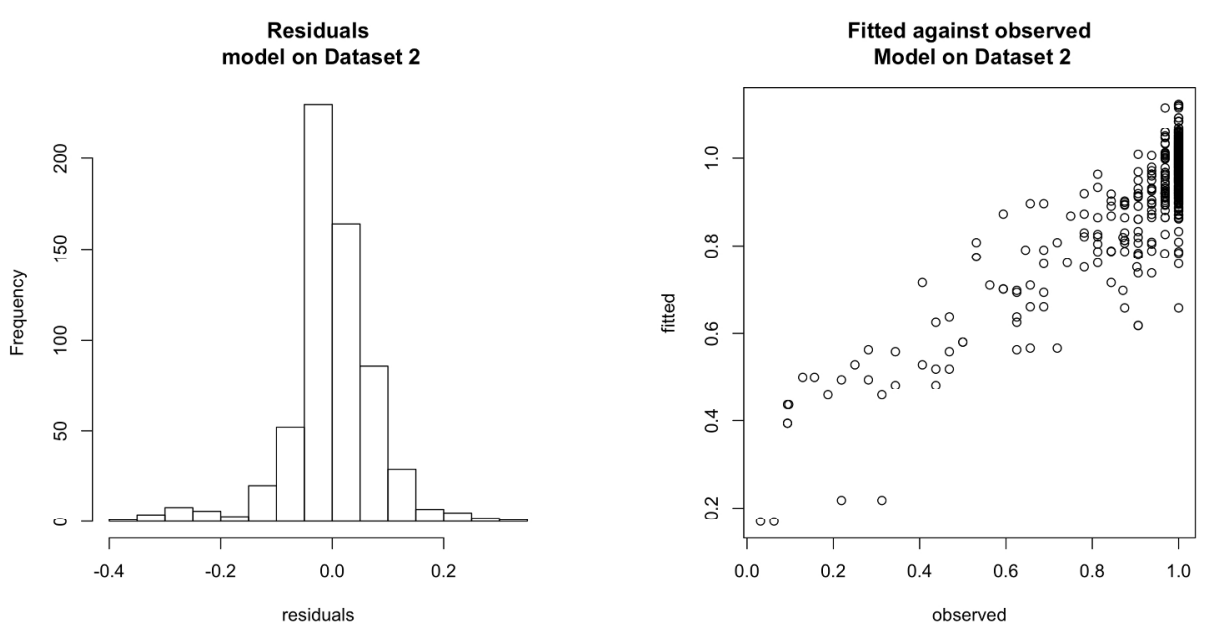

Supplementary Materials 4. Diagnostics for Model 2.

$846 \times 423 \mathrm{~mm}(72 \times 72$ DPI $)$ 
Dataset 2 WM Capacity partial residuals

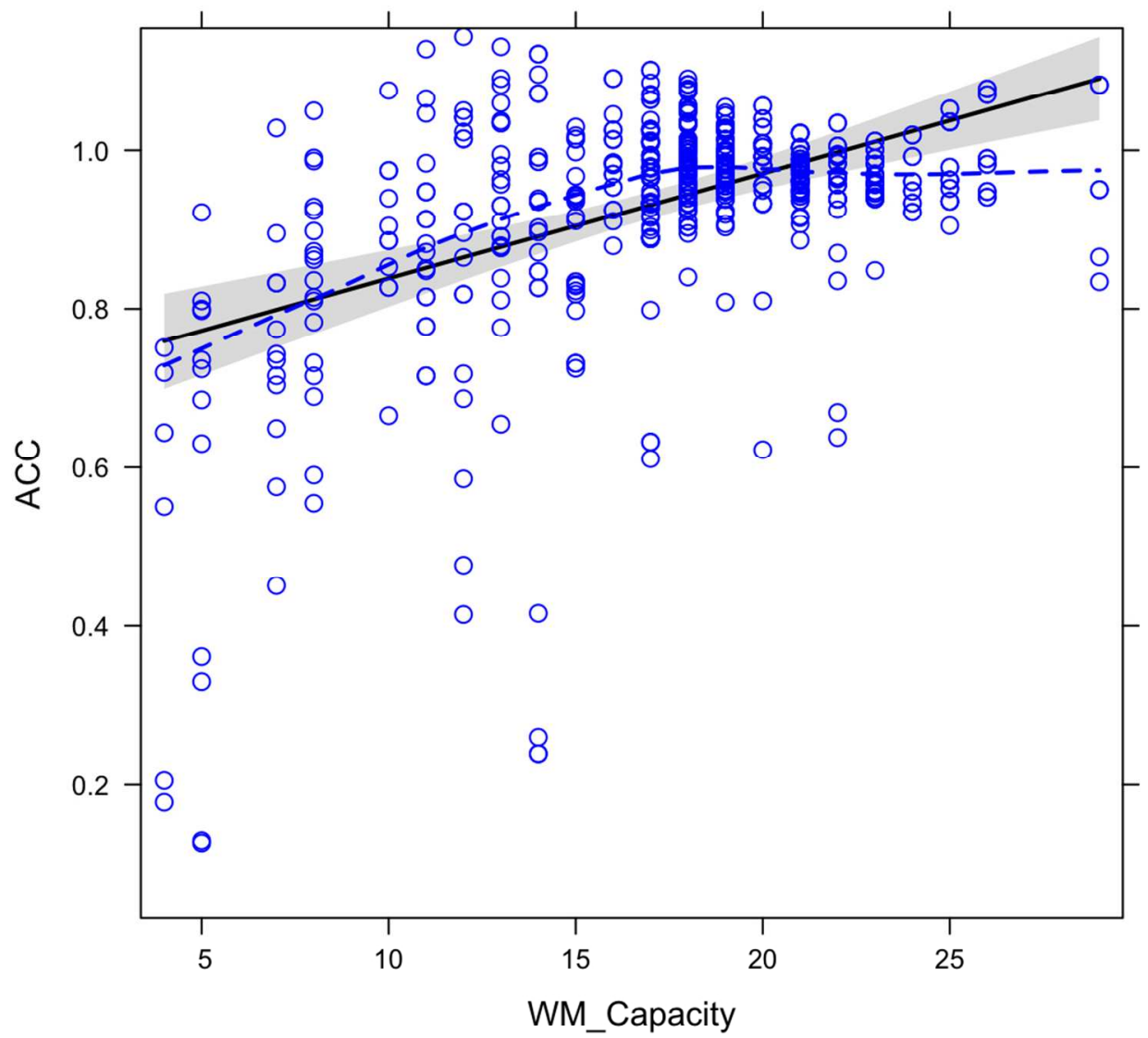

Supplementary Materials 5. Partial residuals for WM in Model 2. $423 \times 423 \mathrm{~mm}(72 \times 72 \mathrm{DPI})$ 
2

3

4

5

Dataset 2 Age partial residuals

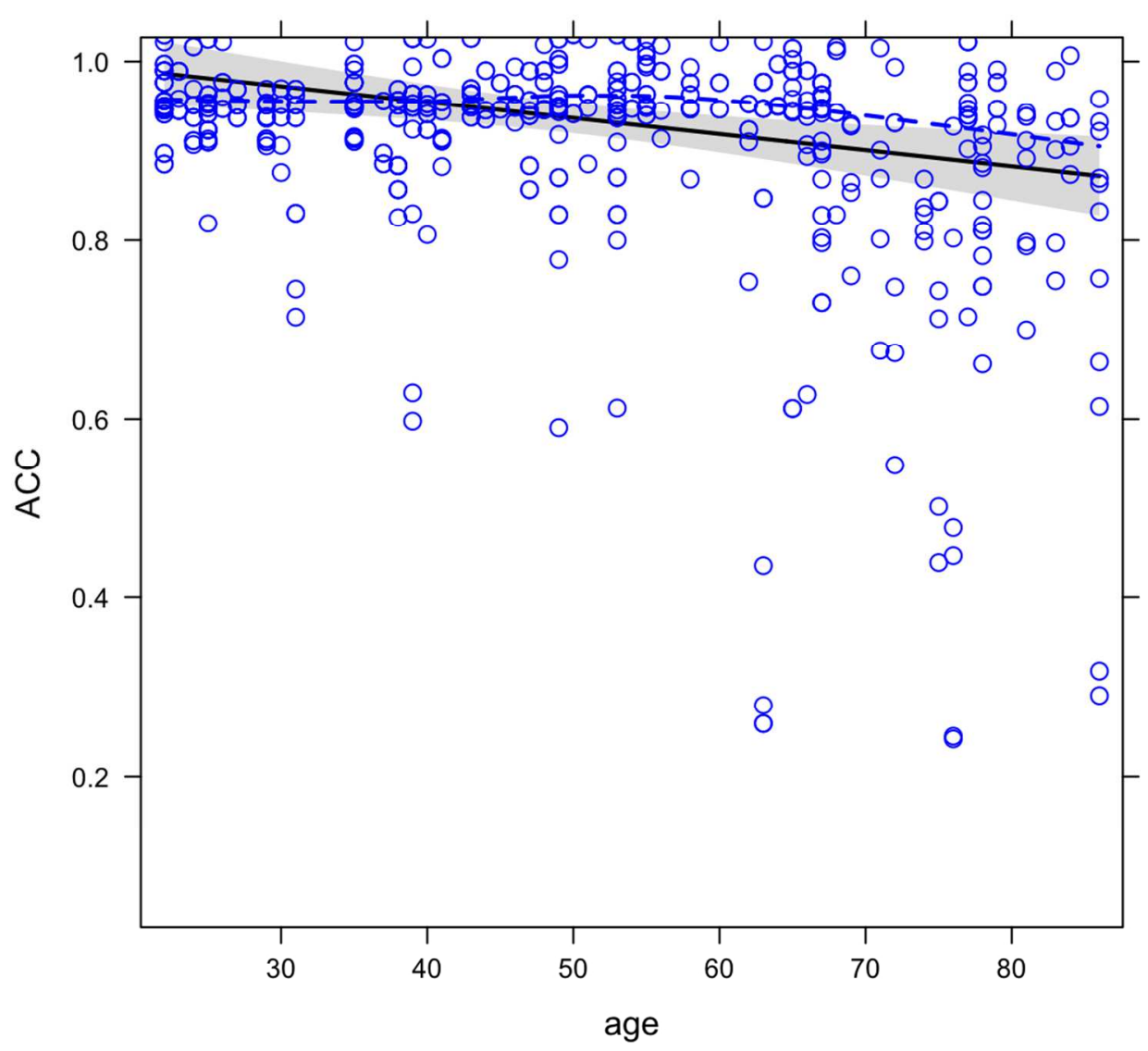

Supplementary Materials 6. Partial residuals for age in Model 2.

$423 \times 423 \mathrm{~mm}(72 \times 72 \mathrm{DPI})$ 
Supplementary Materials 7. Individual performance (correct) of healthy participants on subject-verb agreement, tense, and aspect (with local and nonlocal conditions collapsed).

\begin{tabular}{|c|c|c|c|}
\hline & Agreement & Tense & Aspect \\
\hline \multicolumn{4}{|c|}{$\begin{array}{l}\text { Younger (aged 20- } \\
\text { 39) participants }\end{array}$} \\
\hline HP1 & $64 / 64$ & $64 / 64$ & $64 / 64$ \\
\hline HP2 & $62 / 64$ & $64 / 64$ & $63 / 64$ \\
\hline HP3 & $64 / 64$ & $64 / 64$ & $62 / 64$ \\
\hline HP4 & $64 / 64$ & $64 / 64$ & $64 / 64$ \\
\hline HP5 & $64 / 64$ & $64 / 64$ & $64 / 64$ \\
\hline HP6 & $64 / 64$ & $64 / 64$ & $64 / 64$ \\
\hline HP7 & $64 / 64$ & $64 / 64$ & $64 / 64$ \\
\hline HP8 & $64 / 64$ & $64 / 64$ & $64 / 64$ \\
\hline HP9 & $64 / 64$ & $64 / 64$ & $64 / 64$ \\
\hline HP10 & $64 / 64$ & $64 / 64$ & $63 / 64$ \\
\hline HP11 & $64 / 64$ & $64 / 64$ & $64 / 64$ \\
\hline HP12 & $64 / 64$ & $64 / 64$ & $61 / 64$ \\
\hline HP13 & $64 / 64$ & $64 / 64$ & $63 / 64$ \\
\hline HP14 - 1 & $64 / 64$ & $64 / 64$ & $59 / 64$ \\
\hline HP15 & $64 / 64$ & $63 / 64$ & $64 / 64$ \\
\hline HP16 & $64 / 64$ & $64 / 64$ & $64 / 64$ \\
\hline HP17 & $64 / 64$ & $64 / 64$ & $64 / 64$ \\
\hline HP18 & $64 / 64$ & $64 / 64$ & $64 / 64$ \\
\hline HP19 & $64 / 64$ & $64 / 64$ & $64 / 64$ \\
\hline HP20 & $64 / 64$ & $64 / 64$ & $63 / 64$ \\
\hline HP21 & $64 / 64$ & $64 / 64$ & $64 / 64$ \\
\hline HP22 & $64 / 64$ & $64 / 64$ & $62 / 64$ \\
\hline HP23 & $64 / 64$ & $63 / 64$ & $63 / 64$ \\
\hline HP24 & $64 / 64$ & $64 / 64$ & $62 / 64$ \\
\hline HP25 & $63 / 64$ & $64 / 64$ & $63 / 64$ \\
\hline HP26 & $64 / 64$ & $64 / 64$ & $64 / 64$ \\
\hline HP27 & $64 / 64$ & $64 / 64$ & $64 / 64$ \\
\hline HP28 & $64 / 64$ & $64 / 64$ & $64 / 64$ \\
\hline HР29 - 1 & $64 / 64$ & $60 / 64$ & $43 / 64$ \\
\hline HP30 & $64 / 64$ & $63 / 64$ & $61 / 64$ \\
\hline HP31 & $64 / 64$ & $64 / 64$ & $60 / 64$ \\
\hline HP32 & $64 / 64$ & $64 / 64$ & $63 / 64$ \\
\hline HP33 & $64 / 64$ & $64 / 64$ & $64 / 64$ \\
\hline HP34 & $64 / 64$ & $64 / 64$ & $64 / 64$ \\
\hline \multicolumn{4}{|c|}{ Middle-aged (40- } \\
\hline HP35 & $32 / 32$ & $32 / 32$ & $32 / 32$ \\
\hline HP36 - 1 & $64 / 64$ & $63 / 64$ & $56 / 64$ \\
\hline HP37 & $64 / 64$ & $64 / 64$ & $62 / 64$ \\
\hline
\end{tabular}




\begin{tabular}{|c|c|c|c|}
\hline HP38 & $64 / 64$ & $64 / 64$ & $64 / 64$ \\
\hline HP39 & $63 / 64$ & $64 / 64$ & $61 / 64$ \\
\hline HP40 & $64 / 64$ & $64 / 64$ & $64 / 64$ \\
\hline HP41 - 1 & $64 / 64$ & $64 / 64$ & $57 / 64$ \\
\hline HP42 & $64 / 64$ & $64 / 64$ & $61 / 64$ \\
\hline HP43 & $64 / 64$ & $64 / 64$ & $61 / 64$ \\
\hline HP44 & $64 / 64$ & $64 / 64$ & $64 / 64$ \\
\hline HP45 & $64 / 64$ & $64 / 64$ & $64 / 64$ \\
\hline HP46 & $64 / 64$ & $64 / 64$ & $64 / 64$ \\
\hline HP47 & $64 / 64$ & $64 / 64$ & $64 / 64$ \\
\hline HP48 & $64 / 64$ & $64 / 64$ & $64 / 64$ \\
\hline HP49 & $64 / 64$ & $64 / 64$ & $63 / 64$ \\
\hline HP50 & $64 / 64$ & $64 / 64$ & $60 / 64$ \\
\hline HP51 & $32 / 32$ & $32 / 32$ & $32 / 32$ \\
\hline HP52 & $64 / 64$ & $64 / 64$ & $64 / 64$ \\
\hline HP53 - 1 & $64 / 64$ & $64 / 64$ & $40 / 64$ \\
\hline HP54 & $64 / 64$ & $64 / 64$ & $64 / 64$ \\
\hline HP55 & $64 / 64$ & $64 / 64$ & $63 / 64$ \\
\hline HP56 & $64 / 64$ & $64 / 64$ & $64 / 64$ \\
\hline HP57 & $64 / 64$ & $64 / 64$ & $63 / 64$ \\
\hline HP58 & $64 / 64$ & $64 / 64$ & $64 / 64$ \\
\hline HP59 - 1 & $63 / 64$ & $64 / 64$ & $44 / 64$ \\
\hline HP60 & $64 / 64$ & $64 / 64$ & $64 / 64$ \\
\hline HP61 & $32 / 32$ & $32 / 32$ & $32 / 32$ \\
\hline HP62 & $31 / 32$ & $32 / 32$ & $31 / 32$ \\
\hline HP63 & $64 / 64$ & $64 / 64$ & $60 / 64$ \\
\hline HP64 & $64 / 64$ & $64 / 64$ & $64 / 64$ \\
\hline HP $65-1$ & $64 / 64$ & $64 / 64$ & $58 / 64$ \\
\hline HР66 - 1 & $63 / 64$ & $64 / 64$ & $57 / 64$ \\
\hline HP67 & $64 / 64$ & $64 / 64$ & $62 / 64$ \\
\hline HP68 & $63 / 64$ & $64 / 64$ & $62 / 64$ \\
\hline HР69 & $32 / 32$ & $32 / 32$ & $32 / 32$ \\
\hline \multicolumn{4}{|c|}{$\begin{array}{l}\text { Older (aged 60-86) } \\
\text { participants }\end{array}$} \\
\hline HP70 - 3 & $60 / 64$ & $6 / 64$ & $3 / 64$ \\
\hline HP71 - 1 & $64 / 64$ & $64 / 64$ & $51 / 64$ \\
\hline HP72 - 1 & $62 / 64$ & $58 / 64$ & $29 / 64$ \\
\hline HP73 - 2 & $62 / 64$ & $54 / 64$ & $25 / 64$ \\
\hline HP74 - 1 & $61 / 64$ & $60 / 64$ & $26 / 64$ \\
\hline HP75 - 1 & $59 / 64$ & $54 / 64$ & $29 / 64$ \\
\hline HP76 - 2 & $59 / 64$ & $50 / 64$ & $32 / 64$ \\
\hline HP77 - 2 & $64 / 64$ & $57 / 64$ & $34 / 64$ \\
\hline HP78 - 1 & $63 / 64$ & $64 / 64$ & $40 / 64$ \\
\hline HP79 - 3 & $59 / 64$ & $9 / 64$ & $17 / 64$ \\
\hline HP80 - 2 & $64 / 64$ & $48 / 64$ & $16 / 64$ \\
\hline HP81 - 1 & $63 / 64$ & $62 / 64$ & $42 / 64$ \\
\hline HP82 - 1 & $64 / 64$ & $63 / 64$ & $34 / 64$ \\
\hline HP83 - 1 & $64 / 64$ & $64 / 64$ & $57 / 64$ \\
\hline HP84 - 3 & $63 / 64$ & $43 / 64$ & $45 / 64$ \\
\hline
\end{tabular}




\begin{tabular}{llll} 
HP85 & $64 / 64$ & $64 / 64$ & $64 / 64$ \\
HP86 -3 & $64 / 64$ & $58 / 64$ & $56 / 64$ \\
HP87 -4 & $64 / 64$ & $63 / 64$ & $58 / 64$ \\
HP88 & $64 / 64$ & $64 / 64$ & $61 / 64$ \\
HP89 -2 & $58 / 64$ & $43 / 64$ & $16 / 64$ \\
HP90 - & $63 / 64$ & $51 / 64$ & $38 / 64$ \\
HP91 & $64 / 64$ & $64 / 64$ & $64 / 64$ \\
HP92 & $64 / 64$ & $64 / 64$ & $64 / 64$ \\
HP93 - & $64 / 64$ & $64 / 64$ & $58 / 64$ \\
HP94 - & $64 / 64$ & $64 / 64$ & $57 / 64$ \\
HP95 - & $32 / 32$ & $32 / 32$ & $27 / 32$ \\
HP96 - & $58 / 64$ & $21 / 64$ & $6 / 64$ \\
HP97 - & $63 / 64$ & $54 / 64$ & $39 / 64$ \\
HP98 & $64 / 64$ & $64 / 64$ & $63 / 64$ \\
HP99 - & $64 / 64$ & $64 / 64$ & $55 / 64$ \\
HP100 - & $56 / 64$ & $55 / 64$ & $35 / 64$ \\
HP101 - & $64 / 64$ & $64 / 64$ & $57 / 64$ \\
HP102 & $64 / 64$ & $64 / 64$ & $62 / 64$ \\
HP103 & $64 / 64$ & $64 / 64$ & $63 / 64$ \\
\hline
\end{tabular}

Notes

HP: Healthy participant

1 indicates that the pattern agreement/tense $>$ aspect emerged.

2 indicates that the pattern agreement $>$ tense $>$ aspect emerged.

3 indicates that the pattern agreement $>$ tense/aspect emerged.

4 indicates that the pattern agreement $>$ aspect $\&$ agreement $=$ tense $\&$ tense $=$ aspect emerged.

For all comparisons, Fisher's exact test for count data was employed. 